\title{
The effects of native and modified clupeine on the structure of gram-negative model membranes
}

Article

Accepted Version

Creative Commons: Attribution-Noncommercial-No Derivative Works 4.0

English, M., Paulson, A., Green, R. J., Florek, O., Clifton, L. A., Arnold, T. and Frazier, R. A. (2019) The effects of native and modified clupeine on the structure of gram-negative model membranes. Food Structure, 22. 100127. ISSN 2213-3291 doi: https://doi.org/10.1016/j.foostr.2019.100127 Available at https://centaur.reading.ac.uk/86551/

It is advisable to refer to the publisher's version if you intend to cite from the work. See Guidance on citing.

To link to this article DOI: http://dx.doi.org/10.1016/j.foostr.2019.100127

Publisher: Elsevier

All outputs in CentAUR are protected by Intellectual Property Rights law, including copyright law. Copyright and IPR is retained by the creators or other copyright holders. Terms and conditions for use of this material are defined in the End User Agreement.

www.reading.ac.uk/centaur 
Central Archive at the University of Reading

Reading's research outputs online 


\section{Highlights}

- Similar structural effects were observed for both peptides in the monolayer and bilayer models, however, the magnitude of the effect was greater in the presence of the chemically modified peptide.

- Improved hydrophobicity and electrostatic interactions with lipid head groups resulting in thickening of the peptide layer, along with lipid translocation in the inner tail region of the bilayer, strongly suggests that the modified clupeine may use the carpet mechanisms to exert its effect on model membranes.

- Simultaneous fitting of neutron reflectometry and x-ray reflectometry data from PE:PG:CL monolayer model systems, resulted in quantitative determination of surface excess values for both native and modified clupeine. 


\section{Graphical Abstract}

March 3, 2019 


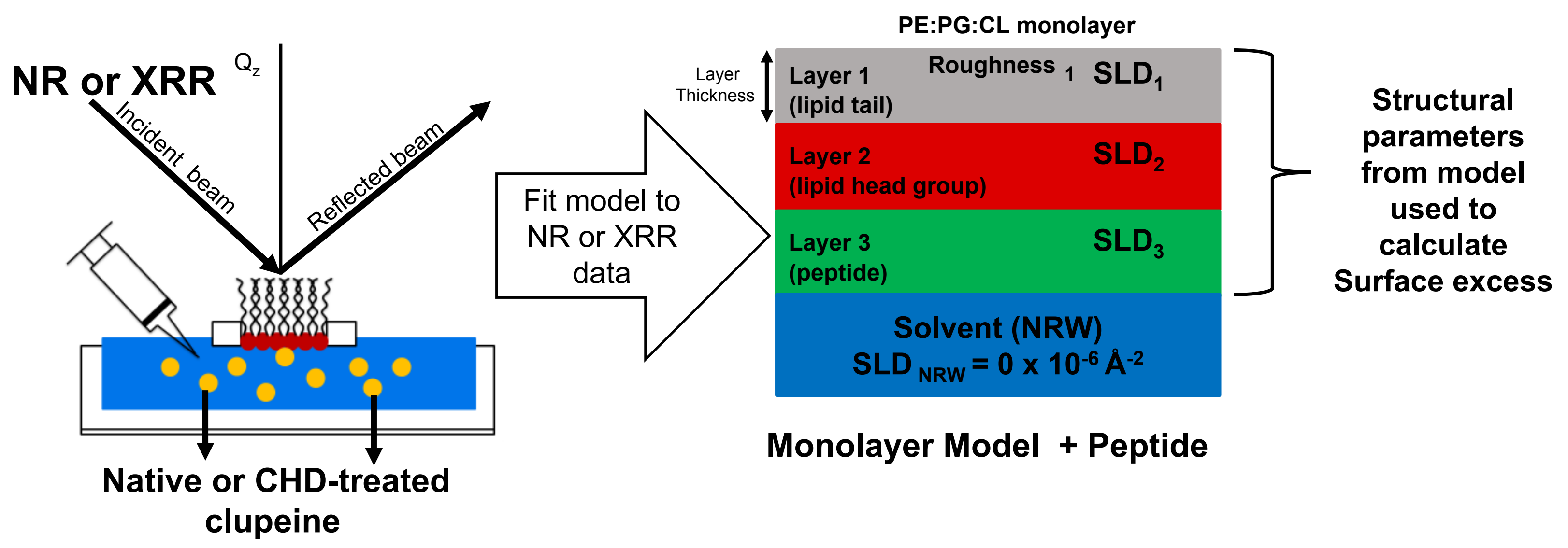


Title: The effects of native and modified clupeine on the structure of Gram-negative model membranes.

Name of authors: M. English ${ }^{\mathrm{a}}$, A. Paulson ${ }^{\mathrm{b}}$, R. J. Green ${ }^{\mathrm{c}}$, O. Florek, L. A. Clifton ${ }^{\mathrm{d}}$, T. Arnolde, $\&$ R. A. Frazierf.

Contact information for corresponding author: Marcia M. English, 2320 Notre Dame Avenue, Antigonish, Nova Scotia, menglish@stfx.ca

All other author affiliations

a Department of Human Nutrition, Saint Francis Xavier University, Antigonish, Nova Scotia; ${ }^{b}$ Department of Process Engineering and Applied Science, Dalhousie University, Halifax, Nova Nova Scotia, Canada.

'School of Pharmacy, University of Reading, Reading, PO Box 226, Whiteknights, Reading, RG6 6AP, UK

${ }^{\mathrm{d} I S I S}$, Science and Technology Facilities Council, Rutherford Appleton Laboratory, Didcot, UK eEuropean Spallation Source, Lund, Sweden

fDepartment of Food and Nutritional Sciences, University of Reading, Reading, Harry Nursten Building, PO Box 226, Whiteknights, Reading, RG6 6AP, UK

Word count of text: "7,254 words"

Short version of title: Structural effects of clupeine in model membranes. 
ABSTRACT: Clupeine, a cationic antimicrobial peptide found in fish, is of interest as a food additive but non-specific binding of the peptide to anionic molecules reduces its antimicrobial activity. The overall positive charge of clupeine can be reduced by blocking $10 \%$ of its arginine residues with 1,2-cyclohexanedione (CHD). The modified peptide retains antimicrobial activity but it is not known if its effect on the structure of Gram-negative model membranes is the same as the native peptide. In the presented paper, neutron reflectometry (NR) and X-ray reflectometry were used to investigate the effect of native and modified clupeine on the structure of model monolayer membranes composed of Phosphatidylethanolamine (PE), Phosphatidylglycerol (PG), and Cardiolipin (CL). The effect of the peptides on the structure of 1,2-dipalmitoyl (d62)-snglycero-3-phosphocholine (DPPC)/PE:PG:CL bilayers were also examined by NR. In both model systems, modified clupeine demonstrated a greater effect on the lipid structure. Charge reduction in the modified sample also resulted in improved hydrophobicity, and the formation of thicker peptide layers in the membrane models. Some lipid translocation was observed in the inner tail region $(\sim 69 \pm 0.24 \%$ DPPC and $\sim 24 \pm 0.02 \%$ PE:PG:CL $)$; and in the outer tail region $(\sim 24 \pm 0.02 \%$ DPPC and $\sim 56 \pm 0.01 \%$ PE:PG:CL). Improved hydrophobicity and electrostatic interactions with lipid head groups, strongly suggests that the modified clupeine may use the carpet mechanisms to exert its effect on model membranes. These findings suggest that changing the charge on the native peptide changes the way in which the modified peptide disrupts Gram-negative model membranes.

Keywords: Clupeine, cationic antimicrobial peptide, Gram-negative bacteria, neutron reflectometry, and X-ray reflectometry, and protamine. 


\section{Introduction}

Bacteria can have both beneficial and harmful effects in food systems. For example, their use as probiotics (lactic acid bacteria) in fermented foods provide beneficial effects on human health (Ohashi \& Ushida, 2009; Doyle, Steenson, \& Meng, 2013). On the other hand, approaches to ensure the safety of food components and to combat illnesses caused by food-borne pathogens must confront the global problem of bacterial resistance (Manyi-Loh, Mamphweli, Meyer, \& Okoh, 2018). Molecular studies have emphasized that the remarkable ability of bacteria to undermine the efficacy of antimicrobial agents is due in part to their ability to adapt under selective pressure and develop resistance through mutations or by acquiring genes from other bacteria (Canu, A., Malbruny, B., Coquemont, M., Davies, T., Appelbaum, P., \& Leclercq, 2002; Spratt, Bowler, Zhang, Zhou, \& Smith, 1994). Thus, for the past three decades, a major scientific priority has been the pursuit of new sources of antimicrobial agents with alternate mechanisms of action, which can limit the development of bacterial resistance (Munita \& Arias, 2016).

In this context, cationic antimicrobial peptides (CAPs) have attracted interest as potential alternatives to conventional antimicrobial agents because they have exhibited broad spectrum inhibitory activity against several foodborne pathogens, and there have only been a few reports of developed resistance (Anaya-López, López-Meza, J., \& Ochoa- Zarzosa, 2013). CAPs are found in many organisms including plants and fish (Omardien, Brul, \& Zaat, 2016), and some can be cheaply extracted from waste streams (Gill, Singer, \& Thompson, 2006). In spite of differences in their overall structure and sequence, many CAPs are characterized by their amphipathic domains, and their polycationic nature due to the presence of lysine, arginine or histidine residues $(\mathrm{Wu}$, Maier, Benz, \& Hancock, 1999).

Several membrane disruption models including the barrel-stave, carpet, and the toroidal pore models have been proposed for CAPs. The validity of these models, and therefore 
antimicrobial activity largely depend on the cationic charge and amphipathic nature of CAPs (Straus \& Hancock, 2006). In the barrel-stave model (BSM), the amphipathic nature of CAPs is utilized, here their hydrophobic peptide regions align into the lipid environment, whereas the hydrophilic side chains are aligned inward to form trans-membrane pores (Brogden, 2005). It is through these pores that cytoplasmic contents can leak from the cell, and result in cell death. Similarly, in the toroidal pore model, CAPs are inserted into the bilayer and cause the latter to bend and form a pore. As a result, phospholipid head groups and polar peptide surfaces line the pore lumen and local aggregations of varied numbers of peptide molecules within the membrane provide a route of passage of ions (Brogden, 2005). On the other hand, in the carpet model, the peptides bind to the cell surface in an electrostatic manner, and form a layer that alters membrane fluidity and or reduces the barrier properties of the membrane (Pelegrini, del Sarto, Silva, Franco, \& Grossi-de-Sa, 2011).

Among CAPs, protamine, is a small peptide (4112 Da) which may be extracted from the sperm cells of fish such as herring (clupeine) and salmon (salmine). Similar to most CAPs protamine is very cationic and consists of 31 amino acids, with 20 of those residues being arginine (Suzuki \& Ando, 1972). However, unlike most CAPs, protamine is not amphipathic, and lacks secondary structure due to the even distribution of positive charges along the peptide backbone (Bonora, Ferrara, Paolillo, Toniolo, \& Trivellone, 1979). Protamine has also exhibited antimicrobial activity toward food-borne pathogenic bacteria but widespread applications in foods are made difficult due to non-specific interactions with food components (Truelstrup Hansen \& Gill, 2000; Ueno, Fujita, Yamamoto, \& Kozakai, 1988). These non-specific interactions can be overcome by chemically blocking arginine residues with 1,2-cyclohexanedione (CHD), which also reduces the surface charge of the peptide (Potter et al., 2005). The CHD-treated peptide also has 
improved antimicrobial activity as demonstrated by reduced growth of Listeria monocytogenes in milk as well as in ground beef (Potter, Truelstrup Hansen, \& Gill, 2005) but the effects of the peptides on bacterial membrane structure is not fully known. Accordingly, our objective was to use two complementary biophysical techniques, neutron reflectometry (NR) and X-ray reflectometry (XRR), to investigate the effect of native and modified clupeine on the structure of model monolayer membranes composed of zwitterionic (Phosphatidylethanolamine, PE), and anionic phospholipids (Phosphatidylglycerol, PG and Cardiolipin, CL). These phospholipids are present in the natural, cytoplasmic membrane of Gram-negative bacteria in an approximate 79:17:4 mole \% ratio (Sohlenkamp \& Otto, 2016). The effect of the peptides on the structure of 1,2dipalmitoyl (d62)-sn-glycero-3-phosphocholine (DPPC)/PE:PG:CL bilayers was also investigated by NR. Understanding the initial steps involved in native and modified clupeine membrane interactions will begin to define characteristics of the peptides and the target bacteria that will be useful in understanding the peptides' mode of action.

\section{Materials and Methods}

\subsection{Materials}

DPPE, 1,2-dipalmitoyl-glycero-3-phosphoethanolamine, MW 691.97 (zwitterionic and synthetic purity > 99\%); DPPG, 1,2-dipalmitoyl-sn-glycero-3-[phosphor-rac-1-glycerol] (anionic sodium salt), MW 744.96; and 1,1'2,2'-tetramyristoyl cardiolipin (anionic sodium salt), MW 1,285.62 were all purchased from Avanti Polar Lipids (Alabaster, AL, USA). Stock solutions of all lipids were prepared using a 3:1 mixture of HPLC grade chloroform to methanol (SigmaAldrich, Oakville, ON, Canada) in a ratio (PE:PG:CL; 79:17:4 mole \%), hereafter referred to as PPC and stored at $-20^{\circ} \mathrm{C}$.. Native clupeine (clupeine sulfate (MW $\left.4112 \mathrm{Da}, \mathrm{P} 4505\right)$ ), L-arginine, 0.1 M HCL solution, CHD (MW $112.13 \mathrm{~g} / \mathrm{mol}$ ), 8-hydroxyquinoline, sodium hydroxide, liquid 
bromine, and HPLC grade chloroform were obtained from Sigma-Aldrich (Oakville, Oakville, ON, Canada):

\subsection{Clupeine Modification}

To reduce the surface charge of arginine CHD (2.8 g) was dissolved in $500 \mathrm{~mL}$ of $0.2 \mathrm{M}$ boric acid buffer ( $\mathrm{pH} 8.5)$ then $2.5 \mathrm{~g}$ of native clupeine was added and the contents of each flask stirred for $20 \mathrm{~s}$ (Potter et al., 2005). The samples were incubated at $37^{\circ} \mathrm{C}$ for $2.5 \mathrm{~min}$ and then 500 $\mathrm{mL}$ of cold $5 \%(\mathrm{v} / \mathrm{v})$ acetic acid was added. Control samples were prepared in a similar manner except that no CHD was added to the reaction flasks. The modified samples were concentrated to $200 \mathrm{~mL}$, and then exhaustively dialyzed in a Prep/Scale Millipore Model P34404 ultrafiltration apparatus (Millipore, Toronto, ON, Canada) equipped with $900 \mathrm{~cm}^{2}, 1000 \mathrm{Da}$ tetrafluoroethylene (TFE) filters and flushed with five volumes of $1 \%(\mathrm{v} / \mathrm{v})$ acetic acid and ten volumes of distilled, deionized water (DDW) and concentrated once again to $200 \mathrm{~mL}$ as described by Potter et al. (2005). Finally, the purified samples were frozen at $-30^{\circ} \mathrm{C}$ and then freeze dried (Labconco, Missouri, USA). Stock solutions were prepared by dissolving $0.1 \mathrm{~g}$ of the powder in $40 \mathrm{~mL}$ of $1 \%$ $(\mathrm{v} / \mathrm{v})$ acetic acid. Working solutions were prepared by diluting the stock solutions 1:50 with DDW. The Sakaguchi reaction (Sakaguchi, 1950; Potter et al., 2005), which is specific for arginine, was used to determine the unmodified arginine residues in the CHD-treated clupeine. The percent modification of arginine residues was determined using an arginine- $\mathrm{HCl}$ standard curve and taking into account that $\sim 20$ of the 30 amino acid residues in clupeine are arginine (Ando et al., 1973).

Only CHD-treated clupeine with $10 \%$ of the arginine residues modified was chosen for further testing because it has been reported that moderate reductions in charge led to improved antimicrobial efficacy (Potter et al., 2005).

\subsection{Peptide Surface Hydrophobicity}


154 a fluorescent probe, 6-propionyl-2-(N,N-dimethylamino) naphthalene (PRODAN) as outlined by Alizadeh-Pasdar and Li-Chan (2000) with modifications. A PRODAN standard curve was

156 developed using concentrations ranging from 0 to $0.95 \mu \mathrm{M}$. Using this PRODAN binding curve,

157 it was possible to measure the amount of PRODAN bound to the peptide samples. PRODAN (20

$158 \mu \mathrm{L}, 7.6 \mathrm{mM})$ was added to $4 \mathrm{~mL}$ of peptide in a $0.01 \mathrm{M}$ phosphate buffer (pH 7). After $15 \mathrm{~min}$

159 incubation in the dark, the relative fluorescent intensity (RFI) was measured using a Photo

160 Technology International (PTI) fluorescence spectrophotometer, with excitation and emission

161 wavelengths set at 390 and $470 \mathrm{~nm}$, respectively.

162

163

164

165

166

167

168

169

170

171

172

173

\subsection{Zeta Potential}

The net charge density of the peptides was measured as zeta potential $(\mathrm{mV})$ using a Zetasizer Nano Model ZS (Malvern Instruments, Derbyshire, UK) as outline by Paulson and Tung (1987) with modifications. Measurements were made at $20^{\circ} \mathrm{C}$ in triplicate. The zeta potential was calculated from the electrophoretic mobility of individual particles, measured using laser Doppler velocimetry (Malvern Instruments Ltd, 2004).

\subsection{Surface Pressure Measurements}

Surface pressure measurements on a Langmuir trough (model 611 Nima Technology, Coventry, England) interfaced with a computer data acquisition system were carried out by the Wilhelmy plate method as described by Lad, Birembaut, Clifton, Frazier, Webster, \& Green, (2007). Clean troughs were filled with $80 \mathrm{~mL}$ of $0.02 \mathrm{M}$ phosphate buffer (pH 7), and $20 \mu \mathrm{L}$ of the lipid solution in chloroform was spread dropwise using a Hamilton syringe (Hamilton Company, Reno, NV) on the surface of the buffer to form a monolayer. The lipid monolayer was compressed to a target surface pressure of $\sim 25 \mathrm{mN} \mathrm{m}^{-1}$. Control checks were carried out for $\sim 4.2$ 
$177 \mathrm{~h}$ on the bare PPC monolayers to determine their stability. For each experiment, the compressed

178 film was relaxed for $20 \mathrm{~min}$ at $\sim 25 \mathrm{mN} \mathrm{m}^{-1}$ prior to the addition of $1 \mathrm{~mL}$ of native or modified

179 clupeine solution to the subphase (final peptide concentration of $0.48 \mu \mathrm{M}$ ). Compression isotherms

180 were recorded as surface pressure $(\pi)$ vs. area (A) curves prior to the addition of the peptides and

181 on addition of the peptide to the subphase, and plots of surface pressure vs. time were recorded to

182 follow adsorption of the peptides to the lipid layer. All compressions were repeated until a

183 reproducible trace was obtained and the final surface pressure values had a standard deviation of

$184 \pm 1 \mathrm{mN} \mathrm{m}^{-1}$. Similar experiments were carried out using the negatively charged phospholipid,

185 DPPG, as a control.

186

187

188

189

190

191

192

193

194

195

196

197

198

199

200

\subsection{Neutron Reflectometry Measurements on PPC}

NR measurements were carried out using the white beam SURF reflectometer at the Rutherford Appleton Laboratory (Didcot, Oxfordshire, UK), using neutron wavelengths from 0.5

to $6.5 \AA$. The beam intensity was calibrated with respect to a clean $\mathrm{D}_{2} \mathrm{O}$ surface. The sample preparation and NR method were carried out as described by Clifton, Sanders, Hughes, Neylon, Frazier, \& Green (2011) with some modifications. Briefly, all the NR experiments were performed at room temperature and the lipid films were prepared by spreading the PPC lipid mix (from the stock solution) in a 200 x 400 mm Langmuir trough (Nima Technology, Coventry, UK) containing a $20 \mathrm{mM}$ phosphate buffer (pH 7.0). Films were compressed to a surface pressure of $23 \mathrm{mN} \mathrm{m}^{-1}$ and the films were relaxed for $20 \mathrm{~min}$ at $23 \mathrm{mN} \mathrm{m}^{-1}$ prior to the addition of native or CHD-treated clupeine solutions $(0.48 \mu \mathrm{M})$ to the lipid monolayer. NR curves were recorded at two angles of incidence $\left(\theta=1.5\right.$ and $\left.0.8^{\circ}\right)$ to yield a momentum transfer range of $\sim 0.01-0.6 \AA^{-1}$ both before and after the addition of native or CHD-treated clupeine. NR was measured under multiple isotopic contrasts and this was achieved by using hydrogenated and deuterated lipids in a non-reflecting 
water subphase compared to air, NRW $\left(8 \% \mathrm{D}_{2} \mathrm{O}, 92 \% \mathrm{H}_{2} \mathrm{O}\right)$, and $\mathrm{D}_{2} \mathrm{O}$. Measurements using hydrogenated lipids (h-lipids) on NRW were done to observe protein binding since the h-lipid will be largely non-reflecting $\left(\rho(h-\right.$ lipid $\left.)=-0.39 \times 10^{-6} \AA^{-2}\right)$, where $\rho$ represents the scattering length density (SLD). Repeat experiments using isotopic contrasts with d-lipid $(\rho(d-$ lipid $)=$ $7.5 \times 10^{-6} \AA^{-2}$ ) on NRW were also done to reveal any changes in lipid layer structure caused by the interaction. Contrasts of h-lipid on $\mathrm{D}_{2} \mathrm{O}$ were also done to enable differentiation between peptide adsorbed beneath the interface and the lipid head group (Clifton, Neylon, \& Lakey 2013a).

\subsection{X-Ray Reflectometry Measurements on PPC}

X-ray reflectometry experiments were performed at the I07 beamline at the Diamond Light Source (Harwell Science and Innovation Campus, Didcot, Oxfordshire, UK). The sample preparation and method described by Clifton et al. (2012) was carried out. Experiments were performed at room temperature and the lipid films were prepared by spreading the PPC lipid mix (from the stock solution) in a $200 \times 400 \mathrm{~mm}$ Langmuir trough containing a $20 \mathrm{mM}$ phosphate buffer ( $\mathrm{pH}$ 7.0). The films were compressed to a surface pressure of $23 \mathrm{mN} \mathrm{m}^{-1}$ and then relaxed for $20 \mathrm{~min}$ at $23 \mathrm{mN} \mathrm{m}^{-1}$ prior to the addition of native or CHD-treated clupeine solutions $(0.48$ $\mu \mathrm{M}$ ). A monochromatic X-ray wavelength of $0.992 \AA \AA$ (corresponding to a photon energy, E of $12.5 \mathrm{keV}$ ) was used and a fast shutter was applied to avoid over-exposure to the X-ray beam.

The experiments were also performed in a helium atmosphere, the reflectivity profiles were measured in a $\mathrm{Q}_{z}$ range of 0.01 to $0.8 \AA^{-1}$ and data were collected on a Dectris Pilatus $100 \mathrm{k}$ detector. XRR data were reduced by performing a normalisation and a "footprint correction" step. There were three parts to the normalisation, the first part involved dividing by the incident flux since this varies with the incident angle. The second part involved stitching the three regions together; by overlapping points at the extremes of each region. The third part involved scaling the 
data so that reflectivity at the critical edge was equal to one. The detector also used two 'regions of interest' (ROI) to simultaneously measure the signal, and this background was subtracted from all the data sets (Clifton et al., 2012).

\subsection{Bilayer Deposition and Neutron Reflectometry Measurements}

Gram-negative model, single bilayer membranes were prepared at the ISIS Biological Sample Laboratory (Rutherford, England) as outlined by Clifton et al. (2013b). NR measurements were carried out using the white beam SURF reflectometer, using neutron wavelengths from 0.5 to $6.5 \AA$. The collimated neutron beam was reflected from the silicon-liquid interface at three different glancing angles of incidence, $0.35^{\circ}, 0.65^{\circ}$ and $1.5^{\circ}$.

A neutron flow-cell was placed at the bottom of a clean Langmuir-Blodgett (LB) trough (KSV-Nima, Biolin Scientific, Finland) and the cell was flushed with ultrapure water (Millipore, 18.2 $\mathrm{M} \Omega \mathrm{cm}^{-1}$ ) to remove air bubbles and was then filled with $20 \mathrm{mM}$ phosphate buffer ( $\mathrm{pH} \mathrm{7.0)}$ A Piranha-cleaned $\left(\mathrm{H}_{2} \mathrm{O}_{2} / \mathrm{H}_{2} \mathrm{SO}_{4} / \mathrm{H}_{2} \mathrm{O}\right.$ 1:4:1) silicon $\left(\mathrm{SiO}_{2}\right)$ crystal was then mounted onto the dipping mechanism of the trough in a vertical position and with the active face away from the center, then the block was submerged under the buffer. Two bilayers were prepared and $150 \mu \mathrm{L}$ of tail-hydrogenated or deuterated 1,2-dipalmitoylphosphatidylcholine (h-DPPC and d-DPPC) in $1 \mathrm{mg} / \mathrm{mL}$ in chloroform, was spread onto the clean water surface. The lipid was compressed to an initial pressure of $10 \mathrm{mN} \mathrm{m}^{-1}$ and then equilibrated for $15 \mathrm{~min}$. The lipid layer was then compressed to $35 \mathrm{mN} \mathrm{m}^{-1}$ at a rate of $3 \mathrm{~mm} \mathrm{~min}^{-1}$. Pressure-area isotherms were recorded to confirm the homogeneity of the film.

For LB deposition of the inner bilayer leaflet, the submerged silicon crystal was lifted through the air-water interface at a rate of $3 \mathrm{~mm} / \mathrm{min}$ and at a constant pressure of $35 \mathrm{mN} \mathrm{m}^{-1}$. The entire LB deposition procedure took $45 \mathrm{~min}$. For Langmuir Schaefer (LS) transfer, a clean neutron 
flow-cell was placed in the bottom of the trough before it was filled with cold $20 \mathrm{mM}$ Hepes buffer (pH 7.2). A monolayer was formed on the surface by adding $150 \mu \mathrm{L}$ of the PE:PG:CL (79:17:4 mole \%) lipid mix, and the latter was compressed to $35 \mathrm{mN} \mathrm{m}^{-1}$. The silicon crystal containing the LB-deposited DPPC monolayer was placed on the dipping mechanism of the trough, with the crystal face parallel to the water surface. The silicon crystal with the deposited LB film was then dipped through the interface at a constant rate of $3 \mathrm{~mm} \mathrm{~min}^{-1}$ and lowered into the neutron flowcell at the bottom of the trough. Native or CHD-treated clupeine $(0.48 \mu \mathrm{M})$ were added to the cell in a $20 \mathrm{mM}$ Hepes buffer ( $\mathrm{pH} 7)$.

\subsection{Reflectivity Data Analysis for Monolayers}

NR and XRR data were analyzed using a Matlab version of RasCal (version 1.1.2, Hughes, A., ISIS Spallation Neutron Source, Rutherford, Appleton Laboratory). In RasCal, structures across the interface were modeled as a series of layers and each layer was described by three main parameters: thickness $(\tau)$, SLD $(\rho)$, and roughness (Clifton et al., 2013a). The SLD of the lipids (head groups and tails), solvents and peptides were calculated using equation 1:

Eq. 1

$$
\rho=\frac{\sum \mathrm{b}}{\mathrm{V}}
$$

Where $b$ represented the SL for each element and V represented the molecular volume (Lad, 2006). The XRR and NR data were first fitted individually then fitted simultaneously as described by Nelson (2006) and Clifton et al. (2012) to place restrictions on the NR fit. The thickness and roughness parameters were linked in a single model and the SLD and background values were allowed to vary (Nelson, 2006).

Bare lipid monolayers with no peptides were divided into two layers, the first, a lipid chain layer containing $\mathrm{CH}_{3}$ and $\mathrm{CH}_{2}$ groups and the second, a head group layer containing the lipid head 
groups (Dabkowska, Fragneto, Hughes, Quinn, \& Lawrence, 2009). This classification was based on two assumptions: (1) the first layer contained only lipid component and the second layer contained only the head group; (2) the second assumption was related to the area per molecule and assumed that this value was the same for both the lipid head group and the tail region (Clifton et al., 2011). However, in order to measure peptide binding to the monolayer, a third layer was included in the model to represent the presence of the peptides below the lipid monolayer (Saunders, Clifton, Frazier, \& Green, 2016). A set of reflectivity profiles measured under the three isotopic contrasts hydrogenated (h)-lipid in NRW; h-lipid in $\mathrm{D}_{2} \mathrm{O}$ and deuterated (d)-lipid in NRW were fitted together and the large difference between the scattering lengths of hydrogen $(-0.56 \mathrm{x}$ $\left.10^{-6} \AA^{-2}\right)$ and deuterium $\left(6.35 \times 10^{-6} \AA^{-2}\right)$ was used to detect the location of different components in the monolayer. The parameters of the measured data were then fitted to the theoretical model until the best fit was achieved. The quality of the fit was also assessed visually. The fitted SLD for each isotopic contrast was related to the volume fraction of each component using equation 2 , where $\Phi$ represented the volume fraction, $\rho$ represented the SLD, $\rho_{(\mathrm{D})}$ and $\rho_{(\mathrm{H})}$ represented the fitted SLD and $\rho_{(\mathrm{D}-\mathrm{L})}-\rho_{(\mathrm{H}-\mathrm{L})}$ represented the calculated SLD.

$$
\Phi(\text { lipid })=\frac{\rho(\mathrm{D})-\rho(H)}{\rho(D-L)-\rho(H-L)}
$$

The SLDs and the molecular volume for the native and CHD-treated peptides were calculated as outlined in the ISIS Biomolecular SLD Calculator (http://psldc.isis.rl.ac.uk/Psldc/). To calculate the SLD for the lipid mixture of PPC, the SLD of each individual lipid head and tail was calculated and then multiplied by its fraction in the mixture. The molecular volumes of the lipid components were calculated using the Molinspiration Property Calculator (http://www.molinspiration.com/cgi-bin/properties). The area per molecule $(A)$ occupied by the 
peptide and the lipid in each layer and the surface excess $(\Gamma)$ for each component in the system were calculated using equations 3 and 4 , where $\mathrm{b}$ represented the scattering length, $\rho$ represents the SLD, and $\tau$ represented the layer thickness obtained from the model fit (Clifton et al., 2011).

$$
A=\frac{\sum \mathrm{b}}{\tau \phi \rho}
$$

\subsection{Reflectivity Data Analysis for Bilayers}

Model biomembranes systems composed of either tail deuterated or tail hydrogenated DPPC as the inner leaflet and hydrogenated-PPC as the outer leaflet were prepared, then NR experiments were carried out using three different solution subphases; (1) $\mathrm{D}_{2} \mathrm{O}(100 \%, \rho=6.35 \mathrm{x}$ $10^{-6} \AA^{-2}$ ); (2) silicon matched water (SMW, $38 \% \mathrm{D}_{2} \mathrm{O}$ and $62 \% \mathrm{H}_{2} \mathrm{O}, \rho=2.07 \times 10^{-6} \AA^{-2}$ ); and (3) $100 \%$ water $\left(\rho=-0.56 \times 10^{-6} \AA^{-2}\right)$. Each deuterated and hydrogenated lipid bilayer was measured under all three isotopic contrasts $\left(\mathrm{D}_{2} \mathrm{O}\right.$; SMW and $\left.\mathrm{H}_{2} \mathrm{O}\right)$ thus resulting in a total of six different reflectivity profiles. The large difference between the SLD for deuterated-DPPC $\left(7.45 \times 10^{-6} \AA^{-2}\right)$ and hydrogenated-DPPC $\left(-0.39 \times 10^{-6} \AA^{-2}\right)$ tail regions made it possible to determine structural parameters from the tail region within each individual bilayer. Reflectivity data were obtained for the six contrasts before and after the addition of native and CHD-treated clupeine and the data were analyzed as described in Clifton et al. (2013) using a Matlab version of RasCal. The three membrane components in the bilayer were DPPC, PPC and water and their individual contributions to the bilayer were determined from the fitted values obtained for the tail deuterated- 
DPPC SLDs in the three subphase mixtures $\left(100 \% \mathrm{D}_{2} \mathrm{O}\right.$, SMW $\left(30 \% \mathrm{D}_{2} \mathrm{O}\right.$ and $100 \%$ water). The $\operatorname{SLD}(\rho)$ of a given layer was related to the three membrane components by the following equation:

$$
\rho=\left(\rho_{D P P C}\right)\left(\phi_{D P P C}\right)+\left(\rho_{P P C}\right)\left(\phi_{P E: P G: C L}\right)+\left(\rho_{\text {Water }}\right)\left(\phi_{\text {Water }}\right)
$$

Where $\rho$ represented the SLD of a given layer and $\rho_{D P P C}, \rho_{P P C}$ and $\rho_{\text {Water }}$ represented the SLD of DPPC, PPC and water respectively, while $\phi_{D P P C}, \phi_{P P C}$ and $\phi_{\text {Water }}$ represented the volume fractions of the same components. Because the DPPC and PPC lipid tail regions do not contain labile hydrogens and would not undergo solvent-contrast-related changes in SLD (Clifton et al., $2013 b)$, the volume fraction of water was determined from the following equation:

0

332

Where $\rho_{\text {water contrast } 1}$ and $\rho_{\text {water contrast } 2}$ represented the SLDs of the same layer in any two of the three contrasts $\left(\mathrm{H}_{2} \mathrm{O}\right.$, SMW or $\left.\mathrm{D}_{2} \mathrm{O}\right)$ used, while $\rho_{\text {water } 1}-\rho_{\text {water } 2}$ represented the SLDs of each solvent mixture. Once the volume fraction of water $\left(\phi_{\text {Water }}\right)$ was determined, then the DPPC fraction in the d-DPPC/h-PPC bilayer system was determined using equation 6.

$$
\phi_{\text {Water }}=\frac{\rho_{\text {water contrast } 1}-\rho_{\text {water contrast } 2}}{\rho_{\text {water } 1}-\rho_{\text {water } 2}}
$$

Eq. 6

$$
\rho-\left(\rho_{\text {water }} \phi_{\text {water }}\right)=\left(\rho_{D P P C \text { tails }}\right)\left(\phi_{D P P C \text { tails }}\right)+\left(\rho_{P P C \text { tails }}\right)\left(\phi_{P P C \text { tails }}\right)^{\text {Eq. } 7}
$$

Equation 7 was used to find the value of $\rho-\left(\rho_{\text {water }} \phi_{\text {water }}\right)$, which was needed in order to fully complete equation 8:

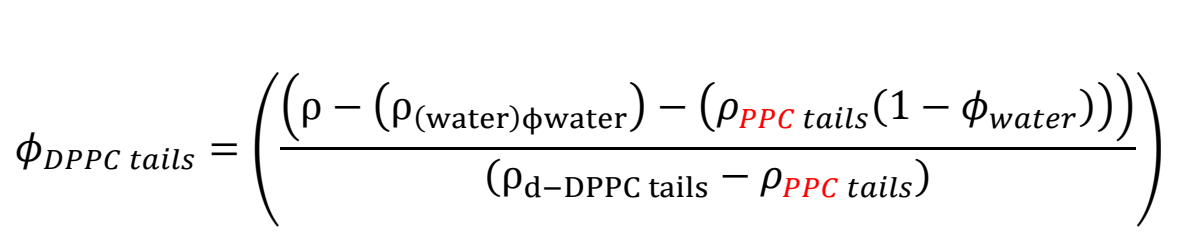

Eq. 8 
344 Once the relative contribution of the $\phi_{D P P C}$ tails were determined, then the relative contributions

345 of the PPC tails to the bilayer were determined by using equation 9:

\subsection{Model to Experimental Data Fitting Analyses}

Eq. 9

The 'bootstrap' error analysis function in RasCal was used to obtain model to experimental data fitting errors as previously described by (Clifton et al., 2012; Clifton et al., 2013b). The original data set was resampled, then new data sets were fitted using the methods described earlier. "The parameter value distributions obtained across these fits were used to estimate errors, and these values were then propagated through the calculations of the derived parameters according to error treatment methods" (Clifton et al., 2013b).

\section{Results and Discussion}

\subsection{Net charge density and surface hydrophobicity}

The native peptide was far less hydrophobic than the modified sample $(\mathrm{P}=0.02, \mathrm{n}=3)$ at the $\mathrm{pH}$ level tested (Figure 1A ). Since the native clupeine is highly cationic in nature, the use of an anionic probe such as 1-anilinonaphthalene-8-sulfonic acid (ANS) would have resulted in greater interaction with the positively charged sites on the peptide, thus overestimating the hydrophobicity. This supports the use of the uncharged probe PRODAN which eliminated the possible electrostatic contributions in the hydrophobicity measurements (Alizadeh-Pasdar \& LiChan, 2000). The measured zeta potential of the native clupeine was $7.2 \pm 0.2 \mathrm{mV}$, which was similar to the value reported by Arbab et al. (2004). Conversely, the modified sample registered a zeta potential of $5.3 \pm 0.1 \mathrm{mV}$.

\subsection{Peptide binding to lipid monolayer using surface pressure measurements}


The surface pressure change on addition of clupeine to a compressed PPC monolayer at the air/water interface was investigated as a function of time (Figure 1). The data showed an increase in surface pressure for CHD-treated clupeine that was not seen for the native peptide. The maximum increase seen after 300 min from addition of the treated clupeine to the subphase was approximately $11 \mathrm{mN} / \mathrm{m}$. This suggests that the CHD-treated clupeine had penetrated into the lipid layer leading to increase compression of the layer, an effect previously reported by (Abuillan et al., 2013; Oliveira et al., 2009). For the native clupeine no increase in surface pressure was observed, although a gradual decrease was seen that could be due to lipid removal at the surface, but was more likely a consequence of the stability of the lipid layer and not an indication of any clupeine interaction. Importantly, this could have been resolved if an equivalent volume of peptidefree buffer was added to the subphase and the same decrease in surface pressure was observed. Conversely, if no effect on surface pressure was observed over the same time period, this would suggest that the peptide did not sit at the air-water surface (Dabkowska et al., 2009).

\subsection{Impact of peptide on lipid monolayer structure}

NR and XRR reflectivity data were fitted simultaneously to provide characterisation of the interfacial layer structure before and after peptide addition. The PPC monolayer characterization prior to peptide addition was determined using two reflectivity profiles, the d-PPC on an NRW buffer subphase (NR) and the h-PPC on a $\mathrm{H}_{2} \mathrm{O}$ phosphate buffer subphase (XRR). Models of the XRR fits are not shown. A two layer model was used to fit the data, where layer 1 was the acyl chain region with a thickness $(\tau)$ of $15 \pm 0.64 \AA$ and a volume fraction $\left(\Phi_{L}\right)$ of $0.97 \pm 0.02$, whereas layer 2 was the lipid head group of the condensed PE:PG:CL monolayer, with a $\tau$ of $12.9 \pm 1.2 \AA$ (Table A2). Ciumac et al. (2017) and Dabkowska et al. (2009) have also reported similarly thin 
hydrophobic chain regions for DPPC or DPPG and for 1,2-dioleoyl-sn-glycero-3-phosphocholine or palmitoyl-oleoyl-glycero-3-phosphoserine (DOPC/ POPS) monolayers.

A third layer was included into the model to allow for fitting of clupeine adsorbed below the lipid layer (Figure 2). In addition, the hydrogenated contrasts in NRW proved to be informative in identifying the contribution of the peptide to the monolayer. As shown in Figure 2 A, the three layer model proposed for native clupeine adsorbed to the condensed phase PPC monolayer, fitted the data well. Peptide binding in the presence of native clupeine showed minimal adsorption in the lipid layer (surface excess $(\Gamma)=0.005 \pm 0.02$ ), but a greater effect was observed in the lipid head group region $(\Gamma=0.297 \pm 0.02)$ and a thickening of the peptide layer $(\tau$, increased from $15.0 \pm$ $0.01 \AA$ to $15.3 \pm 0.07 \AA$ ). Conversely, in the presence of the modified peptide a greater effect on the structure of the monolayer was observed (Figure 3). For example, there was a $25 \%$ and $15 \%$ increase in surface excess and a peptide layer thickness, respectively, compared to the measured values in the presence of the native peptide (Table 1). Slight increases in SLD, $1.07 \pm 0.06 \times 10^{-}$ ${ }^{6} \AA^{-2}$ or $1.69 \pm 0.05 \times 10^{-6} \AA^{-2}$ in the presence of native or CHD-treated clupeine, respectively, were also observed (Table 1). Notable, the difference in the fitted SLDs and the total adsorbed peptide was almost two-fold in the presence of the modified peptide compared to the native peptide.

The requirement of a third layer below the monolayer supports the observation from the surface pressure studies for the modified clupeine, and confirms that the peptide interacted with the PE:PG:CL monolayer (Figure 1). More importantly, the advantage of using two different techniques to characterize peptide interaction with the PPC monolayer is emphasized since, NR is sensitive to the total amount of material at the interface. Thus although the presence of native clupeine on the PPC monolayer led to a decrease in surface pressure change, NR measurements clearly revealed a thickening of the layer (Table1). Work with Puroindoline-b (pin-b) protein 
mutants has also shown little change in surface pressure when the proteins were inserted onto DPPC or DPPG monolayers, however, similar to native and CHD-treated clupeine, NR revealed most of the peptide situated below the lipid region (Clifton, Lad, Green, \& Frazier, 2007; Clifton, Green, Hughes, \& Frazier, 2008). Moreover, NR and XRR methods were advantageous since differences in the radiation source (XRR versus NR) result in different scattering length densities (SLD), and selective SLD modification with deuterium $\left(\mathrm{D}_{2} \mathrm{O}\right)$ labeling made it possible to reveal subtle changes in membrane structure in the presence of the peptides (Lopez-Rubioa, \& Gilbert, 2009).

\subsection{Impact of Peptides on Bilayer Structure}

To validate that the trends observed with the monolayer work were not dependent on the lipid layer model used, bilayer studies were performed. Figure 4 shows the NR profiles and data fits of bilayers in the presence of native (4A), and modified clupeine (4B) examined under threesolution contrasts $\left(\mathrm{D}_{2} \mathrm{O}, \mathrm{SMW}\right.$ and $\left.\mathrm{H}_{2} \mathrm{O}\right)$. In the outer lipid head group region there was a change in SLD from 2.5 to 2.2 or $2.3 \times 10^{-6} \AA^{-2}$ in the presence of native or modified clupeine, respectively (Table 2). The decrease in SLD may be explained by lipid removal from the bilayer in the presence of the peptides. Lipid loss was also accompanied by an increase in hydration of the lipid head group, from $17.9 \pm 12.7 \%$ on the bare bilayer compared to $26.9 \pm 5.5 \%$ in the presence of native clupeine and $48.2 \pm 11.5 \%$ in the presence of the modified clupeine. The greater degree of hydration in the lipid head group region in the presence of modified peptide compared to the native peptide is observed as a broader peak in Figure $4 \mathrm{D}$ compared to Figure $4 \mathrm{~F}$ and may also indicate greater solvent penetration.

The model used to fit the reflectivity data from the deuterated lipids (Figure 4B) showed that it was possible to form asymmetric bilayers with $\sim 90 \%$ DPPC inner leaflet composition and 
442 an outer layer of $\sim 80 \%$ PPC. Although it is now known how closely the model membrane fits the

443 real membrane, similar percent coverages have been reported by Fernandez et al. (2013). Lipid

444 translocation was also observed in the inner tail region $(\sim 69 \pm 0.24 \%$ DPPC and $\sim 24 \pm 0.02 \%$ PPC $)$

445 and in the outer tail region $(\sim 24 \pm 0.02 \%$ DPPC and $\sim 56 \pm 0.01 \%$ PPC) (Table 2). Lipid

446 translocation may have resulted due to lateral heterogeneity in the bilayer which leads to the

447 formation of domains (Epand, 2013). Vorobyov and Allen (2011) discussed the importance of

448 bilayer charge in mediating peptide interaction and showed that adsorption of cationic peptides to

449 anionic bilayers is significantly higher than in zwitterionic membranes. Importantly, electrostatic

450 interactions between peptides and anionic lipids has also been postulated as another factor that

451 supports the formation of domains (Epand, 2013). In the present study it is possible that the

452 peptides could exert part of their effect by changing lateral organization in the membrane.

453 Increased hydrophobicity of the modified clupeine may also explain the increased magnitude of

454 the effect on the lipid structure. Furthermore, thicker peptide layers in the presence of the modified

455 peptide $(11.04 \pm 6.0 \AA$ versus $4.15 \pm 2.9 \AA$ in the presence of the native peptide) (Table 2$)$, implies

456 the accumulation of peptides to form a layer that can interact with negatively charged components

457 in the membrane. Thus, it appears that both hydrophobic and electrostatic interactions may govern

458 the mode of action of the modified clupeine, and strongly suggests that the modified clupeine may

459 use the carpet mechanisms to exert its effect on model membranes. These observations support the

460 findings of Pink, Hasan, Quinn, Winterhalter, Mohan, and Gill (2014) who reported that native

461 clupeine can internalize and kill some Gram-negative bacteria without lysis or pore formation.

462 Conclusion

The initial interactions of native and CHD-treated clupeine in model membranes has been

464 investigated by combining NR and XRR techniques. In the less complex monolayer system, 
465 quantitative amounts of peptides could be determined as surface excess values in the presence of 466 both peptides. Lipid translocation was observed in the inner acyl chains of the bilayer membrane 467 however, but the peptides were not able to penetrate the bilayer membrane. Similar effects on the 468 model membrane structure were observed, although peptide perturbation of the membranes 469 appeared different. Increased hydrophobicity along with electrostatic interactions of the modified 470 peptide were attributed to the improved peptide-lipid interactions. A more comprehensive 471 understanding of the safety and toxicology of these peptide is required before they can be 472 considered for food applications in Canada.

473 Acknowledgments

474 The authors acknowledge support from the Natural Sciences and Engineering Research Council

475 of Canada and a direct access beamtime award. We thank Dr. Michael Sanders for assistance 476 with the surface pressure experiments, and Dr. Filip Ciesielski and Dr. Arwel Hughes for 477 technical assistance during the bilayer experiments.

478 Author Contributions

479 M. English analysed the data and drafted the manuscript. L. Clifton and O. Florek contributed to 480 the acquisition of NR data and the interpretation of the results. T. Arnold assisted with the 481 collection of the X-ray data. A. Paulson, R. Green and R. Frazier contributed to critically 482 revising the manuscript and giving final approval of the version to be submitted. 


\section{References}

490

491

492

493

494

495

496

497

498

499

500

501

502

503

504

505

506

507

508

509

510

511

512

513

514

515

516

517

518

519

520

521

522

523

524

525

526

527

528

529

530
Abuillan, W., Schneck, E., Korner, A., Brandenburg, K., Gutsmann, T., Gill, T., Vorobiev, A., Konovalov, O., \& Tanaka, M. (2013). Physical interactions of fish protamine and antisepsis peptide drugs with bacterial membranes revealed by combination of specular $\mathrm{x}$-ray reflectivity and grazing-incidence $\mathrm{x}$-ray fluorescence. Physical Review, 88, 1-11. doi:10.1103/PhysRevE.88.012705

Alizadeh-Pasdar, N., \& Li-Chan, E. (2000). Comparison of protein surface hydrophobicity measured at various $\mathrm{pH}$ values using three different fluorescent probes. Journal of Agricultural Food Chemistry, 48, 328-334. doi: 10.1021/jf990393p

Anaya-López, J., López-Meza, J., and Ochoa- Zarzosa, A. (2013) Bacterial resistance to cationic antimicrobial peptides. Critical Reviews in Microbiology, 39, 180-195. doi: 10.3109/1040841X.2012.699025

Arbab, A., Yocum, G., Kalish, H., Jordan, E., Anderson, S., Khakoo, A., Read, E., \& Frank, J. (2004). Efficient magnetic cell labeling with protamine sulfate complexed to ferumoxides for cellular. MRI. Blood, 104, 1217-1223. https://doi.org/10.1182/blood-2004-02-0655.

Bonora, G., Ferrara, L., Paolillo, L., Toniolo, C., \& Trivellone E. (1979). 13C Nuclear magnetic resonance of protamines. The three main components of clupeine. European Journal of Biochemistry, 93: 13-21.

Boyle, C., Hansen, L., Hinnenkamp, C., \& Ismail, B. (2018). Emerging Camelina protein: extraction, modification, and structural/functional characterization. Journal of the American Oil Chemists Society, 95, 1049-1062. doi: 10.1002/aocs.12045

Broniatowski, M., Mastalerz, P., \& Flasiński, M. (2015). Studies of the interactions of ursanetype bioactive terpenes with the model of Escherichia coli inner membrane -Langmuir monolayer approach. Biochimica et Biophysica Acta, 1848, 469-476. doi.org/10.1016/j.bbamem.2014.10.024

Canu, A., Malbruny, B., Coquemont, M., Davies, T., Appelbaum, P., \& Leclercq, R. (2002). Diversity of ribosomal mutations conferring resistance to Macrolides, Clindamycin, Streptogramin, and Telithromycin in Streptococcus pneumoniae. Antimicrobial Agents and Chemotherapy, 46, 125-131. doi: 10.1128/AAC.46.1.125-131.2002

Ciumac, D., Campbell, R., Xu, H., Clifton, L., Hughes, A., Webster, J., Lu, J. (2017). Implications of lipid monolayer charge characteristics on their selective interactions with a short antimicrobial peptide. Colloids and Surfaces B: Biointerfaces, 150, 308-316. doi.org/10.1016/j.colsurfb.2016.10.043 
Clifton, L., Ciesielski, F., Skoda, M., Paracini, N., Holt, S., \& Lakey, J. (2016). The effect of lipopolysaccharide core oligosaccharide size on the electrostatic binding of antimicrobial proteins to models of the Gram-negative bacterial outer membrane. Langmuir, 32, 34853494. doi: 10.1021/acs.langmuir.6b00240

Clifton, L., Skoda, M., Le Brun, A., Ciesielski, F., Kuzmenko, I., Holt, S., \& Lakey, J. (2015). Effect of divalent cation removal on the structure of gram-negative bacterial outer membrane models. Langmuir, 31, 404-412. doi: 10.1021/la504407v

Clifton, L., Neylon, C., \& Lakey, J. (2013a). Examining protein-lipid complexes using neutron scattering. Methods in Molecular Biology, 974, 119-150. doi: 10.1007/978-1-62703-275$9+7$

Clifton, L., Skoda, M., Daulton, E., Hughes, A., Le Brun, A., Lakey, J., \& Holt, S. (2013b) Asymmetric phospholipid: lipopolysaccharide bilayers; a Gram-negative bacterial outer membrane mimic. Journal of the Royal Society Interface, 10, 1-11. doi:10.1098/rsif.2013.0810

Clifton, L., Sanders, M., Hughes, A., Neylon, C., Frazier, R., and Green, R. (2011). Lipid binding interactions of antimicrobial plant seed defence proteins: puroindoline- $\alpha$ and $\beta$ purothionin. Physical Chemistry Chemical Physics, 13, 17153-17162. doi: $10.1039 / \mathrm{c} 1 \mathrm{cp} 21799 \mathrm{~b}$

Clifton, L. A., Green, R. J., Hughes, A. V., \& Frazier, R. A. (2008). Interfacial structure of wildtype and mutant forms of Puroindoline-b bound to DPPG monolayers. The Journal of Physical Chemistry B, 112, 15907-15913.

Clifton, L. A., Lad, M. D., Green, R., J., \& Frazier, R. A. (2007). Single amino acid substitutions in Puroindoline-b mutants influence lipid binding properties. Biochemistry, 46, 22602266.

Dabkowska, A., Fragneto, G., Hughes, A., Quinn, P., \& Lawrence, M. (2009). Specular neutron reflectivity studies of the interaction of Cytochrome $\mathrm{c}$ with supported phosphatidylcholine bilayers doped with phosphotidylserine. Langmuir, 25, 4203-4210. doi: $10.1021 / \mathrm{la} 802926 \mathrm{k}$

Del Nobile, M., Conte, A., Cannarsi, M., \& Sinigaglia, M. (2009). Strategies for prolonging the shelf life of minced beef patties. Journal of Food Safety, 29, 14-25. doi: 10.1111/j.17454565.2008.00145.x

Doyle, M., Steenson, L., \& Meng, J. (2013). Bacteria in food and beverage production. In: Prokaryotes, applied bacteriology and biotechnology. Rosenberg, E., DeLong, E., Lory, S., Stackebrandt, E., and Thompson, F. (Ed.), 241- 256. Springer Berlin Heidelberg.

Epand R.M. (2013) Lipid Domains. In: Roberts G.C.K. (Eds) Encyclopedia of Biophysics. Springer, Berlin, Heidelberg. https://doi.org/10.1007/978-3-642-16712-6 
602

603

604

605

606

607

608

609

610

611

612

613

614

615

616

617

618

619

620

621
Fernandez, D., Le Brun, A., Whitwell, T., Sani, M., James, M., \& Separovic, F. (2012). The antimicrobial peptide aurein 1.2 disrupts model membranes via the carpet mechanism. Physical Chemistry Chemical Physics, 14, 15739-15751. doi: $10.1039 / \mathrm{c} 2 \mathrm{cp} 43099 \mathrm{a}$

Gerelli, Y., Porcar, L., and Fragneto, G. (2012). Lipid rearrangement in DSPC/DMPC bilayers: a neutron reflectometry study. Langmuir, 28, 15922-15928. doi: 10.1021/la303662e

Gill, T., Singer, D., \& Thompson, J. (2006). Purification and analysis of protamine. Process Biochemistry, 41, 1875-1882. doi: :10.1016/j.procbio.2006.04.001

Green, R., Su, T., Lu, J., Webster, J., \& Penfold, J. (2000). Competitive adsorption of lysozyme and C12E5 at the air/liquid interface. Physical Chemistry Chemical Physics, 2, 52225229. doi: 10.1039/B004359L

Haskard, C. and Li-Chan, E. (1998). Hydrophobicity of Bovine Serum Albumin and Ovalbumin determined using uncharged (PRODAN) and anionic (ANS-) fluorescent probes. Journal of Agricultural Food Chemistry, 46, 2671-2677

Keymanesh, Soltani, \& Sardari, (2009). Application of antimicrobial peptides in agriculture and food industry. World Journal of Microbiology and Biotechnology, 25, 933-944. doi: org/10.1007/s11274-009-9984-7

Lad, M., Birembaut, F., Frazier, R., \& Green, R. (2005). Protein-lipid interactions at the air/water interface. Physical Chemistry Chemical Physics, 7, 3478- 3485. doi: 10.1039/b506558p

Lad, M., Birembaut, F., Clifton, L., Frazier, R., Webster, J., \& Green, R. (2007). Antimicrobial peptide-lipid binding interactions and binding selectivity. Biophysical Journal, 92, 35753586. doi: 10.1529/biophysj.106.097774

Lopez-Rubioa, A., \& Gilbert, E. (2009). Neutron scattering: a natural tool for food science and technology research. Trends in Food Science and Technology, 20, 576- 586. doi:10.1016/j.tifs.2009.07.008

Manyi-Loh, C., Mamphweli, S., Meyer, E., \& Okoh, A. (2018). Antibiotic use in agriculture and its consequential resistance in environmental sources: potential public health implications. Molecules, 23, 795; doi:103390/molecules23040795

Munita, J. \& Arias, C. (2016). Mechanisms of antibiotic resistance. Microbiology Spectrum, 4(2). doi:10.1128/microbiolspec

Nakano, M.; Fukuda, M.; Kudo, T.; Endo, H.; Handa, T. (2007). Determination of Interbilayer and transbilayer lipid transfers by time-resolved small-angle neutron scattering. Physical Review Letters, 98. doi:238101-238104. 
Nelson, A. (2006). Co-refinement of multiple-contrast neutron/X-ray reflectivity data using MOTOFIT. Journal of Applied Crystallography, 39, 273-276. doi: doi.org/10.1107/S002188980600507

Ohashi, Y. \& Ushida, K. (2009). Health-beneficial effects of probiotics: Its mode of action. Animal Science Journal, 80, 361-371 doi: 10.1111/j.1740-0929.2009.00645.x

Oliveira, R., Schneck, E., Quinn, B., Konovalov, O., Brandenburg, K., Seydel, U., Gill, T., Hanna, C., Pink, D., Tanaka, M. (2009). Physical mechanisms of bacterial survival revealed by combined grazing-incidence $\mathrm{X}$-ray scattering and Monte Carlo simulation. Chimie, 12, 209-217. doi: 10.1016/j.crci.2008.06.020

Omardien, S., Brul, S., and Zaat, S. (2016).Antimicrobial activity of cationic antimicrobial peptides against Gram-positives: current progress made in understanding the mode of action and the response of bacteria. Frontiers in Cell and Developmental Biology, 4, 116. doi.org/10.3389/fcell.2016.00111

Parisio, G., Ferrarini, A., and Sperotto, M. (2016). Model studies of lipid flip-flop in membranes. International Journal of Advances in Engineering Sciences and Applied Mathematics, 8, 134-146. doi: 10.1007/s12572-015-0155-9

Pelegrini, P., del Sarto, R., Silva, O., Franco, O., \& and Grossi-de-Sa, M. (2011). Antibacterial peptides from pants: What they are and how they probably work. Biochemistry Research International, 2011, 1-9. http://dx.doi.org/10.1155/2011/250349

Pink, D., Truelstrup Hansen, L., Gill, T., Quinn, B., Jericho, M., \& Beveridge, T. (2003). Divalent calcium ions inhibit the penetration of protamine through the polysaccharide brush of the outer membrane of Gram-negative bacteria. Langmuir, 19, 8852-8858. doi: $10.1021 / 1 \mathrm{la} 030193 \mathrm{e}$

Pink, D., Hasan, F., Quinn, B., Winterhalter, M., Mohan, M., \& Gill, T. (2014). Interaction of protamine with Gram-negative bacteria membranes: possible alternative mechanisms of internalization in Escherichia coli, Salmonella Typhimurium and Pseudomonas aeruginosa. Journal of Peptide Science, 20, 240-250. doi: 10.1002/psc.2610

Pinto, M., Carvalho, A., Pires, S., Campus, A., Fonseca da Silva, H., Sobral, D., dePaula, J., \& de lima Santos, A. (2011). The effects of nisin on Staphylococcus aureus count and the physicochemical properties of traditional Minas Serro cheese. International Dairy Journal, 21, 90-96. doi: doi.org/10.1016/j.idairyj.2010.08.001

Potter, R., Truelstrup Hansen, L., \& Gill, T. (2005). Inhibition of foodborne bacteria by native and modified protamine: Importance of electrostatic interactions. International Journal of Food Microbiology, 103, 23-34. doi: 10.1016/j.ijfoodmicro.2004.12.019 
Sanders, M., Clifton L., Frazier, R., and Green, R. (2016). Role of lipid composition on the interaction between a tryptophan-rich protein and model bacterial membranes. Langmuir, 32, 2050-2057. doi: 10.1021/acs.langmuir.5b04628

Sohlenkamp, C., \& Geiger, O. (2016). Bacterial membrane lipids: diversity in structures and pathways. FEMS Microbiology Reviews, 40, 133-159. https://doi.org/10.1093/femsre/fuv008

Spratt, B., Bowler, L., Zhang, Q., Zhou, J., \& Smith, J. (1992). Role of interspecies transfer of chromosomal genes in the evolution of penicillin resistance in pathogenic and commensal Neisseria species. Journal of Molecular Evolution, 34:115-125. doi: org/10.1007/BF00182388

Straus, S. \& Hancock, R. (2006). Mode of action of the new antibiotic for Gram-positive pathogens daptomycin: Comparison with cationic antimicrobial peptides and lipopeptides. Biochimica et Biophysica Acta, 1758, 1215-1223. doi:10.1016/j.bbamem.2006.02.009

Strömstedt, A., Ringstad, L., Schmidtchen, L., Malmsten, M. (2010). Interaction between amphiphilic peptides and phospholipid membranes. Current Opinion in Colloid and Interface Science, 15, 467-478. doi: org/10.1016/j.cocis.2010.05.006

Suzuki, K., \& Ando, T. (1972). Studies on protamine: XVII. The complete amino acid sequence of clupeine YI. Journal of Biochemistry, 72, 1433- 1446.

Truelstrup Hansen, L., Austin, J. \& Gill, T. (2001). Antibacterial effect of protamine in combination with EDTA and refrigeration. International Journal of Food Microbiology, 66, 149-161. doi: org/10.1016/S0168-1605(01)00428-7

Ueno, R. Fujita, Y., Yamamoto, M., \& Kozakai, H. (1988). Multiplication inhibitor for Bacillus cerus. European patent application, 0372091. European Patent Office, Great Britain.

Vorobyov, I., \& Allen, T. (2011). On the role of anionic lipids in charged protein interactions with membranes. Biochimica et Biophysica Acta, 1808, 1673-1683. doi.org/10.1016/j.bbamem.2010.11.009

Wu, M., Maier, E., Benz, R., \& Hancock, R. (1999). Mechanism of interaction of different classes of cationic antimicrobial peptides with planar bilayers and the cytoplasmic membrane of the Escherichia coli. Biochemistry, 38, 7235-7242. doi: 10.1021/bi9826299 


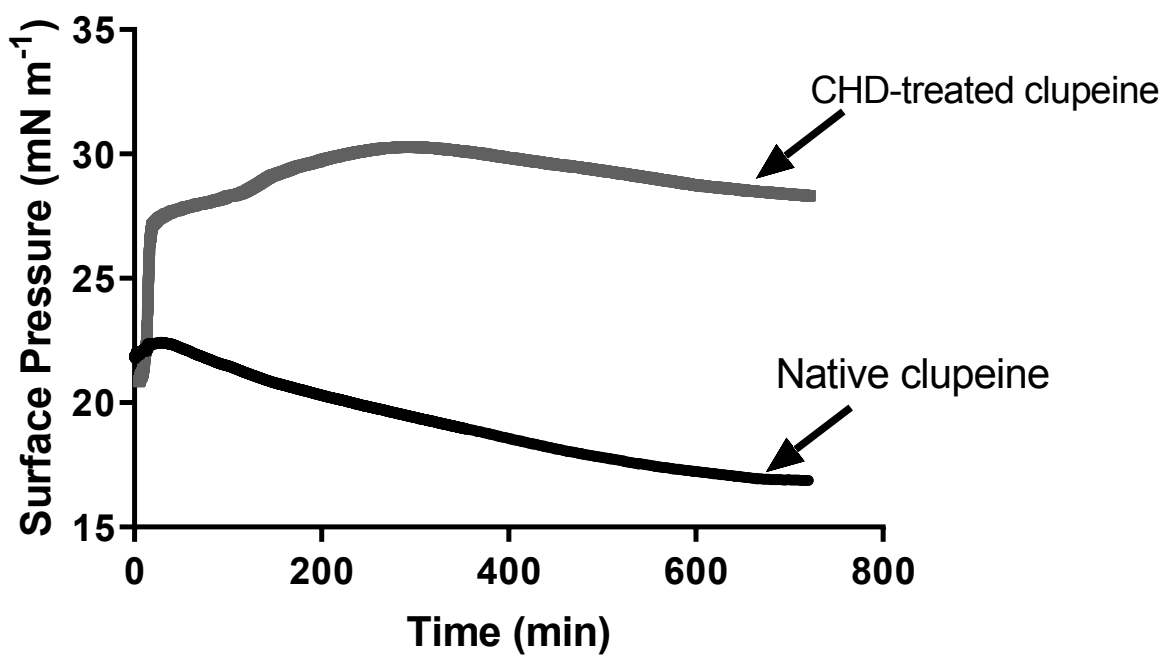

Figure 1. Surface pressure versus time plot for CHD-treated clupeine and native clupeine adsorbed on a PPC monolayer. There was a general increase $(4.6 \%)$ in surface pressure after adding the CHD-treated peptide. On the other hand, the addition of the native peptide resulted in a decrease $(2.3 \%)$ in surface pressure. These experiments were repeated twice.

722

723

*Note that PPC is the abbreviation of PE:PG:CL. 
A.

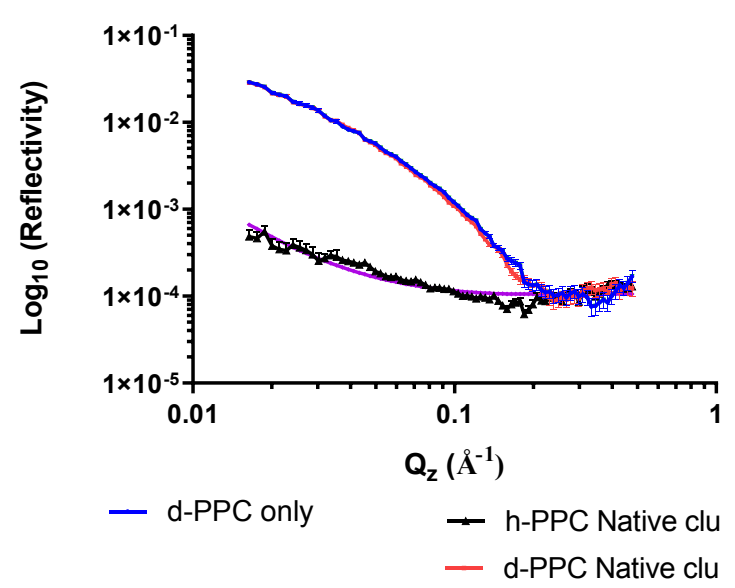

B.

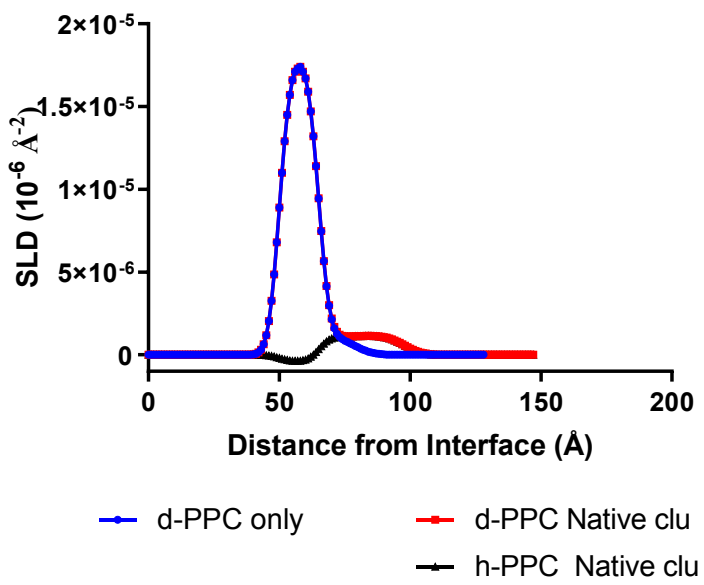

734

Figure 2. Neutron and X-ray reflectometry profiles and model data fits, and corresponding SLD profiles after equilibrium adsorption of native clupeine. (A) Reflectivity of PPC lipid monolayer in NRW with adsorbed native clupeine on the deuterated lipid in (red) and the hydrogenated lipid in (black) is plotted against $\mathrm{Q}_{z}\left(\AA^{-1}\right)$, the momentum transfer. The bare lipid with no peptide is shown in blue and the experimental data are represented with error bars whereas the best fit simulated data are represented as continuous lines. The SLD profile as a function of distance from the interface as determined from the fit is shown in (B).

*Note that PPC is the abbreviation of PE:PG:CL. 
A.

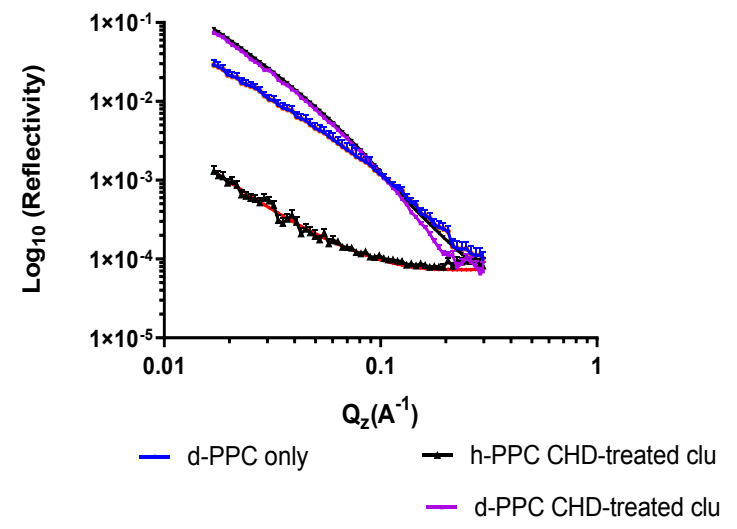

B.

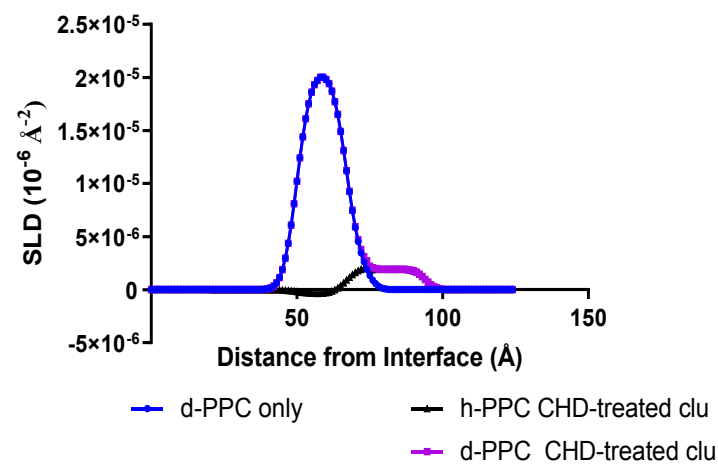

Figure 3. Neutron and X-ray reflectometry profiles and model data fits, and corresponding SLD profiles after equilibrium adsorption of CHD-treated clupeine. (A) Reflectivity of PE:PG:CL monolayer in NRW with adsorbed CHD-treated clupeine on the deuterated lipid in (purple) and the hydrogenated lipid in (black). The bare lipid with no peptide is shown in blue and the experimental data are represented with error bars whereas the best fit simulated data are represented as lines. The SLD profile as a function of distance from the interface as determined from the fit is shown in (B).

\footnotetext{
*Note that PPC is the abbreviation of PE:PG:CL.
} 


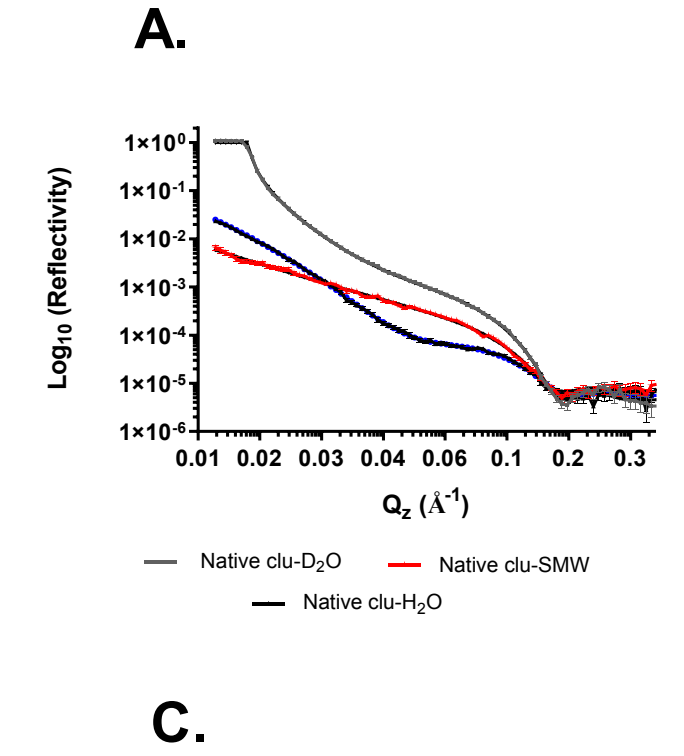

B.
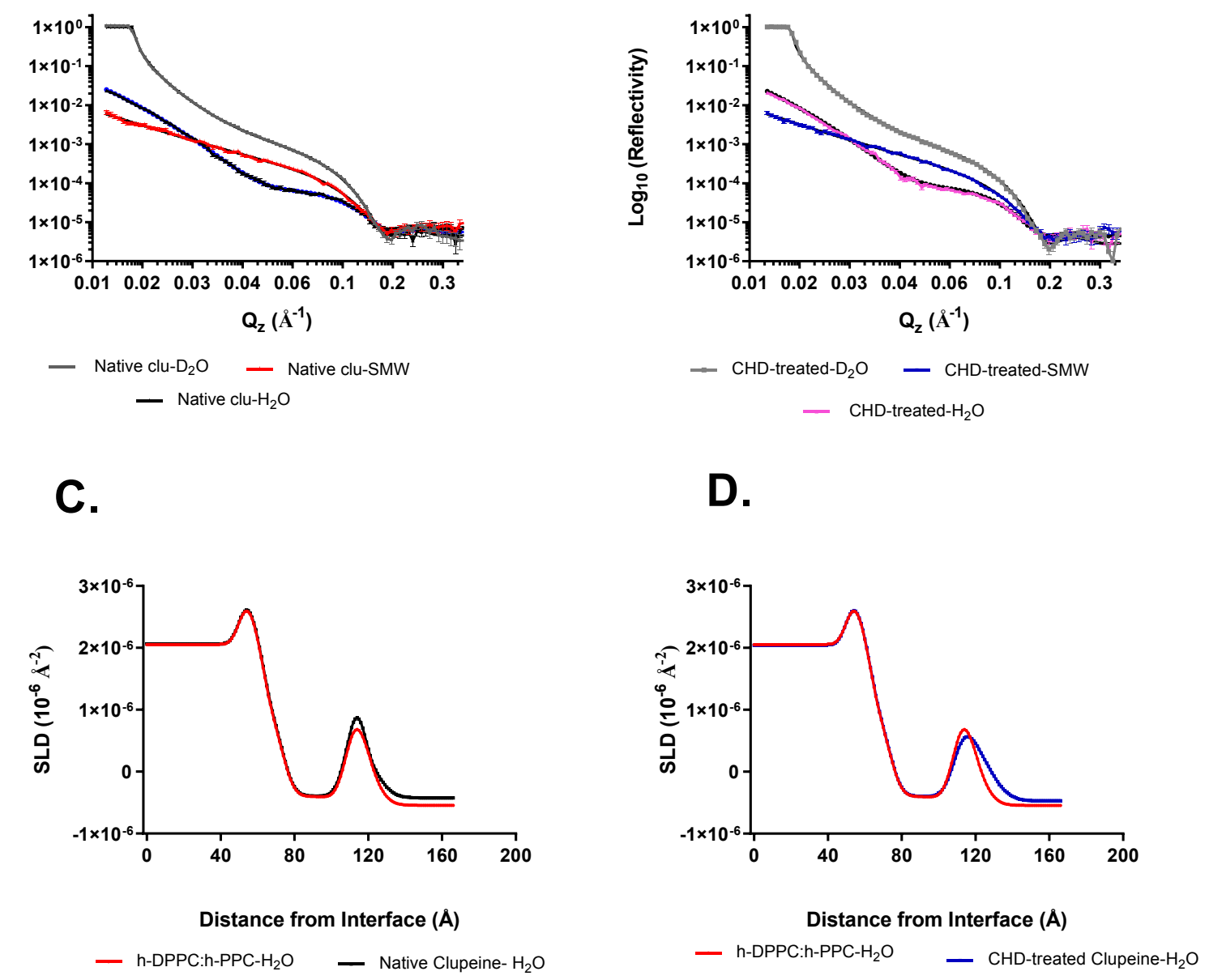

Figure 4. Reflectivity curves and SLD profiles from d/h-DPPC:h-PPC lipid bilayer. A. Reflectivity data for the h-DPPC:h-PPC bilayer lipids in $\mathrm{D}_{2} \mathrm{O}$ (gray), SMW (red), and $\mathrm{H}_{2} \mathrm{O}$ (black) containing native clupeine. The corresponding fits are shown as lines, $\mathrm{D}_{2} \mathrm{O}$ (black), SMW (black), and $\mathrm{H}_{2} \mathrm{O}$ (blue). B. Reflectivity data for the h-DPPC:h-PPC bilayer lipids in $\mathrm{D}_{2} \mathrm{O}$ (grey), SMW (blue), and $\mathrm{H}_{2} \mathrm{O}$ (pink) containing CHD-treated clupeine. The fits are shown as black lines for all contrasts. C. SLD profiles for the bilayer in water contrast in the presence of native clupeine. The data are plotted as points with error bars and the fits are represented as a black line. SLD profile for bilayer in water contrast in the presence of CHD-treated clupeine. The data are plotted as points with error bars and the fits are represented as a blue line. The greater degree of hydration in the lipid head group region in the presence of CHD-treated clupeine compared to the native peptide is observed as a broader peak in Figure $4 \mathrm{D}$ compared to Figure $4 \mathrm{C}$. 
800 Table 1 Structural parameters obtained from the three layer model fits of native and CHD-

801 treated clupeine $(0.48 \mu \mathrm{M})$ adsorbed to PPC monolayers. The fits were repeated three times.

\begin{tabular}{|c|c|c|c|c|c|}
\hline Parameters & $\begin{array}{l}\text { Thickness } \\
\tau(\AA)\end{array}$ & $\begin{array}{l}\text { SLD } \\
\left(10^{-6} \AA^{-2}\right)\end{array}$ & $\begin{array}{l}\text { Layer } \\
\text { roughness } \\
(\AA) \\
\end{array}$ & $\begin{array}{l}\Gamma \text { Surface } \\
\text { excess } \\
\left(\mathbf{m g} / \mathbf{m}^{2}\right) \\
\end{array}$ & $\begin{array}{l}\left.\Phi_{L}\right) \text { Lipid } \\
\text { volume } \\
\text { fraction }\end{array}$ \\
\hline \multicolumn{6}{|c|}{ Layer 1, acyl chain } \\
\hline d-PPC, NRW & $15.0 \pm 0.01$ & $1.60 \pm 0.01$ & $3.51 \pm 0.15$ & $0.005 \pm 0.02$ & $0.59 \pm 0.02$ \\
\hline h-PPC, NRW & $15.0 \pm 0.01$ & $-0.37 \pm 0.01$ & & & \\
\hline h-PPC, XRR & $15.0 \pm 0.01$ & $9.69 \pm 0.03$ & & & \\
\hline \multicolumn{6}{|l|}{$\begin{array}{l}\text { Layer } 2 \text {, head } \\
\text { group }\end{array}$} \\
\hline d- PPC, NRW & $12.7 \pm 0.01$ & $1.07 \pm 0.06$ & & $0.297 \pm 0.02$ & \\
\hline h- PPC, NRW & $12.7 \pm 0.01$ & $1.07 \pm 0.06$ & & & \\
\hline h- PPC, XRR & $12.7 \pm 0.01$ & $12.9 \pm 0.40$ & & & \\
\hline \multicolumn{6}{|c|}{ Layer 3, peptide } \\
\hline d-PPC, NRW & $15.3 \pm 0.07$ & $1.00 \pm 0.09$ & $3.88 \pm 0.32$ & $0.364 \pm 0.02$ & \\
\hline h- PPC, NRW & $15.3 \pm 0.07$ & $1.00 \pm 0.01$ & & & \\
\hline h- PPC, XRR & $15.3 \pm 0.07$ & $10.9 \pm 0.01$ & & & \\
\hline
\end{tabular}

\begin{tabular}{|c|c|c|c|c|c|}
\hline \multicolumn{6}{|c|}{ Layer 1 , acyl chain } \\
\hline d- PPC, NRW & $16.5 \pm 0.14$ & $2.08 \pm 0.05$ & \multirow[t]{7}{*}{$3.83 \pm 0.06$} & \multirow[t]{3}{*}{$0.007 \pm 0.03$} & $0.69 \pm 0.03$ \\
\hline h- PPC, NRW & $16.5 \pm 0.14$ & $-0.37 \pm 0.01$ & & & \\
\hline h- PPC, XRR & $16.5 \pm 0.14$ & $8.64 \pm 0.01$ & & & \\
\hline \multicolumn{5}{|c|}{ Layer 2 , head group } & \\
\hline d- PPC, NRW & $8.27 \pm 0.06$ & $1.69 \pm 0.05$ & & \multirow[t]{3}{*}{$0.372 \pm 0.03$} & \\
\hline h- PPC, NRW & $8.27 \pm 0.06$ & $1.69 \pm 0.05$ & & & \\
\hline h- PPC, XRR & $8.27 \pm 0.06$ & $12.5 \pm 0.06$ & & & \\
\hline \multicolumn{6}{|c|}{$\begin{array}{l}\text { Layer } 3 \text {, peptide } \\
\text { layer (CHD) }\end{array}$} \\
\hline d- PPC, NRW & $17.6 \pm 0.05$ & $1.42 \pm 0.44$ & \multirow[t]{3}{*}{$3.50 \pm 0.44$} & \multirow[t]{3}{*}{$0.59 \pm 0.14$} & \\
\hline h- PPC, NRW & $17.6 \pm 0.05$ & $1.22 \pm 0.25$ & & & \\
\hline h- PPC, XRR & $17.6 \pm 0.05$ & $9.25 \pm 0.05$ & & & \\
\hline
\end{tabular}

802

803

804

805

806

807

808

809 $\tau$, represents layer thickness; $\Gamma$, represents, clupeine surface excess; and $\Phi_{\mathrm{L}}$ represents lipid volume fraction

*Note that PPC is the abbreviation of PE:PG:CL. 
Table 2. Best fit values and error estimates of asymmetrically deposited bare h-DPPC (inner leaflet) E. coli PPC (outer leaflet) bilayer deposited on a silicon surface and the bilayer in the presence of native and CHD-treated clupeine.

\begin{tabular}{|c|c|c|c|}
\hline Parameters of the Bilayer & $\begin{array}{l}\text { Bare } h- \\
\text { bilayer }\end{array}$ & $\begin{array}{l}\text { h-bilayer }+ \\
\text { native clupeine }\end{array}$ & $\begin{array}{l}\text { h-bilayer + } \\
\text { CHD- treated } \\
\text { clupeine }\end{array}$ \\
\hline Oxide layer thickness $(\AA)$ & $11.9 \pm 2.6$ & $\mathrm{nf}$ & $\mathrm{nf}$ \\
\hline Oxide layer hydration (\%) & $15.6 \pm 2.4$ & & \\
\hline Oxide layer roughness $(\AA)$ & $3.58 \pm 0.95$ & & \\
\hline Inner head gp SLD $\left(10^{-6} \AA^{-2}\right)$ & $1.53 \pm 0.01$ & $\mathrm{nf}$ & $\mathrm{nf}$ \\
\hline Inner head group hydration (\%) & $31.3 \pm 5.5$ & & \\
\hline Inner head group thickness $(\AA)$ & $11.9 \pm 3.3$ & & \\
\hline Inner tail SLD $\left(10^{-6} \AA^{-2}\right)$ & -0.39 & $\mathrm{nf}$ & $\mathrm{nf}$ \\
\hline Inner tail hydration (\%) & $8.18 \pm 1.5$ & & \\
\hline Inner tail thickness $(\AA)$ & $15.7 \pm 2.2$ & & \\
\hline Outer tail SLD $\left(10^{-6} \AA^{-2}\right)$ & -0.39 & $\mathrm{nf}$ & $\mathrm{nf}$ \\
\hline Outer tail hydration (\%) & $4.45 \pm 0.93$ & & \\
\hline Outer tail thickness $(\AA)$ & $19.2 \pm 0.89$ & & \\
\hline Outer head gp SLD $\left(10^{-6} \AA^{-2}\right)$ & $2.51 \pm 0.30$ & $2.17 \pm 0.50$ & $2.27 \pm 0.48$ \\
\hline Outer head group hydration (\%) & $17.9 \pm 12.7$ & $26.9 \pm 5.5$ & $48.2 \pm 12$ \\
\hline Outer head group thickness $(\AA)$ & $7.94 \pm 0.54$ & $8.52 \pm 0.04$ & $8.13 \pm 0.66$ \\
\hline Bilayer roughness $(\AA)$ & $4.99 \pm 0.01$ & $\mathrm{nf}$ & $\mathrm{nf}$ \\
\hline Clupeine hydration (\%) & n.a. & $48.8 \pm 3.1$ & $58.9 \pm 15$ \\
\hline Clupeine thickness $(\AA)$ & n.a. & $4.15 \pm 2.9$ & $11.0 \pm 6.0$ \\
\hline Clupeine roughness $(\AA)$ & n.a. & $3.15 \pm 2.7$ & $6.91 \pm 1.6$ \\
\hline
\end{tabular}




\section{Appendix A}

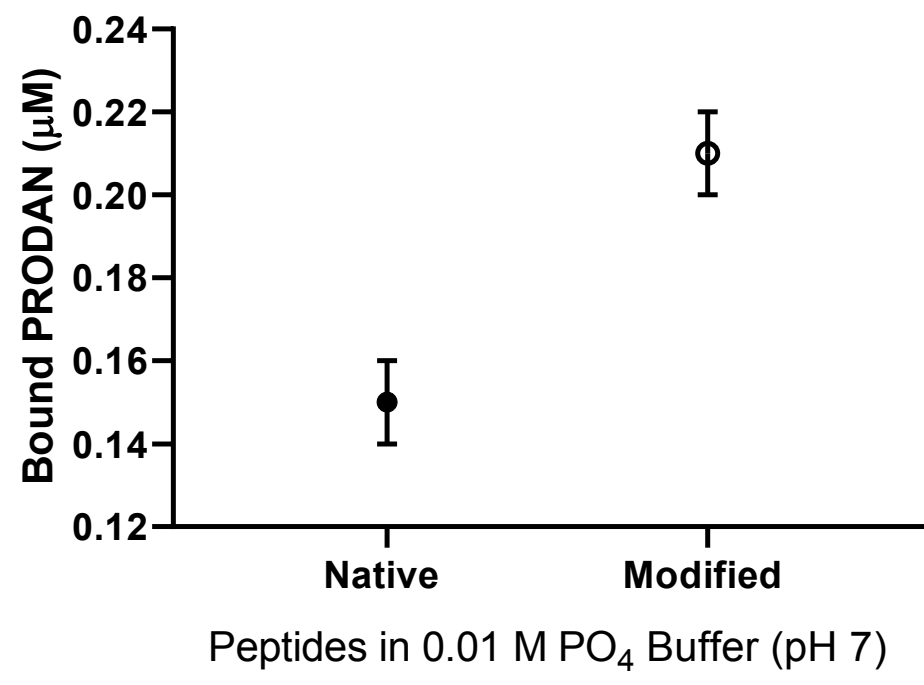

Figure 1A. The binding of PRODAN to native and modified clupeine. The surface hydrophobicity of the native and modified clupeine was measured using an uncharged probe, PRODAN. A PRODAN standard curve was developed which was used to measure the amount of probe bound to the clupeine samples. 
Table A1. Summary of Scattering length scattering length densities, molecular weights, and molecular volumes of the lipids (PPC and DPPC) and peptides used in the present study.

\begin{tabular}{|c|c|c|c|c|}
\hline Parameters & $\begin{array}{l}\text { Scattering } \\
\text { length } \sum \mathbf{b} \\
\left(1^{-3} \AA\right)\end{array}$ & $\begin{array}{l}\text { SLD } \\
\left(10^{-6} \AA^{-2}\right)\end{array}$ & $\begin{array}{l}\text { Molecular } \\
\text { Weight } \\
\text { (g/mol) }\end{array}$ & $\begin{array}{l}\text { Molecular } \\
\text { Volume }\left(\AA^{3}\right)\end{array}$ \\
\hline h-PPC (head + tail) & 0.339 & 0.300 & 720 & 1128 \\
\hline h-PPC (hd. group) & 0.598 & 2.06 & 273 & 288 \\
\hline d-PPC tail & 6.24 & 7.49 & 496 & 838 \\
\hline h-PPC tail & -0.326 & -0.394 & 434 & 838 \\
\hline Native clupeine in NRW & 29.0 & 2.02 & 4200 & \\
\hline $\begin{array}{l}\text { CHD-treated clupeine in } \\
\text { NRW }\end{array}$ & 29.0 & 2.02 & 4200 & \\
\hline h-DPPC (head + tail) & 0.277 & 0.241 & 734 & 1152 \\
\hline h-DPPC (hd. group) & 0.597 & 1.74 & 311 & 342 \\
\hline h-DPPC tail & & $-0.39^{a}$ & & \\
\hline d-DPPC tail & & $7.45^{\mathrm{a}}$ & & \\
\hline
\end{tabular}

${ }^{a}$ These values were obtained from Clifton et al. (2013 b). 
Table A2 Structural parameters obtained from a two-layer model fit of a condensed phase dPE:PG:CL monolayer obtained from simultaneously fitting NR and XRR profiles. The structural parameters described for each layer are the layer thickness $(\tau)$, the SLD $(\rho)$ and the corresponding layer roughness. The fits were repeated three times.

\begin{tabular}{lcccc}
\hline \multicolumn{1}{c}{ Parameters } & $\begin{array}{c}\text { Thickness } \\
\boldsymbol{\tau}(\mathbf{\AA})\end{array}$ & $\begin{array}{c}\text { SLD } \\
\left(\mathbf{1 0}^{-\mathbf{6}} \AA^{-\mathbf{2}}\right)\end{array}$ & $\begin{array}{c}\text { Layer } \\
\text { roughness }(\boldsymbol{\AA})\end{array}$ & $\begin{array}{c}\text { Lipid volume } \\
\text { fraction }\left(\boldsymbol{\Phi}_{\mathbf{L}}\right)\end{array}$ \\
\hline Layer 1, acyl chain & & & & \\
d-PE:PG:CL, NR & $15.0 \pm 0.64$ & $7.28 \pm 0.76$ & $3.93 \pm 1.1$ & $0.97 \pm 0.02$ \\
h-PE:PG:CL, XRR & $15.0 \pm 0.64$ & $9.55 \pm 0.49$ & & \\
Layer 2, head & & & \\
group & & & \\
d-PE:PG:CL, NR & $12.9 \pm 1.2$ & $0.46 \pm 0.25$ & \\
h-PE:PG:CL, XRR & $12.9 \pm 1.2$ & $13.2 \pm 0.07$ & \\
\hline
\end{tabular}

$\tau$, represents layer thickness and $\Phi_{\mathrm{L}}$, represents lipid volume. 


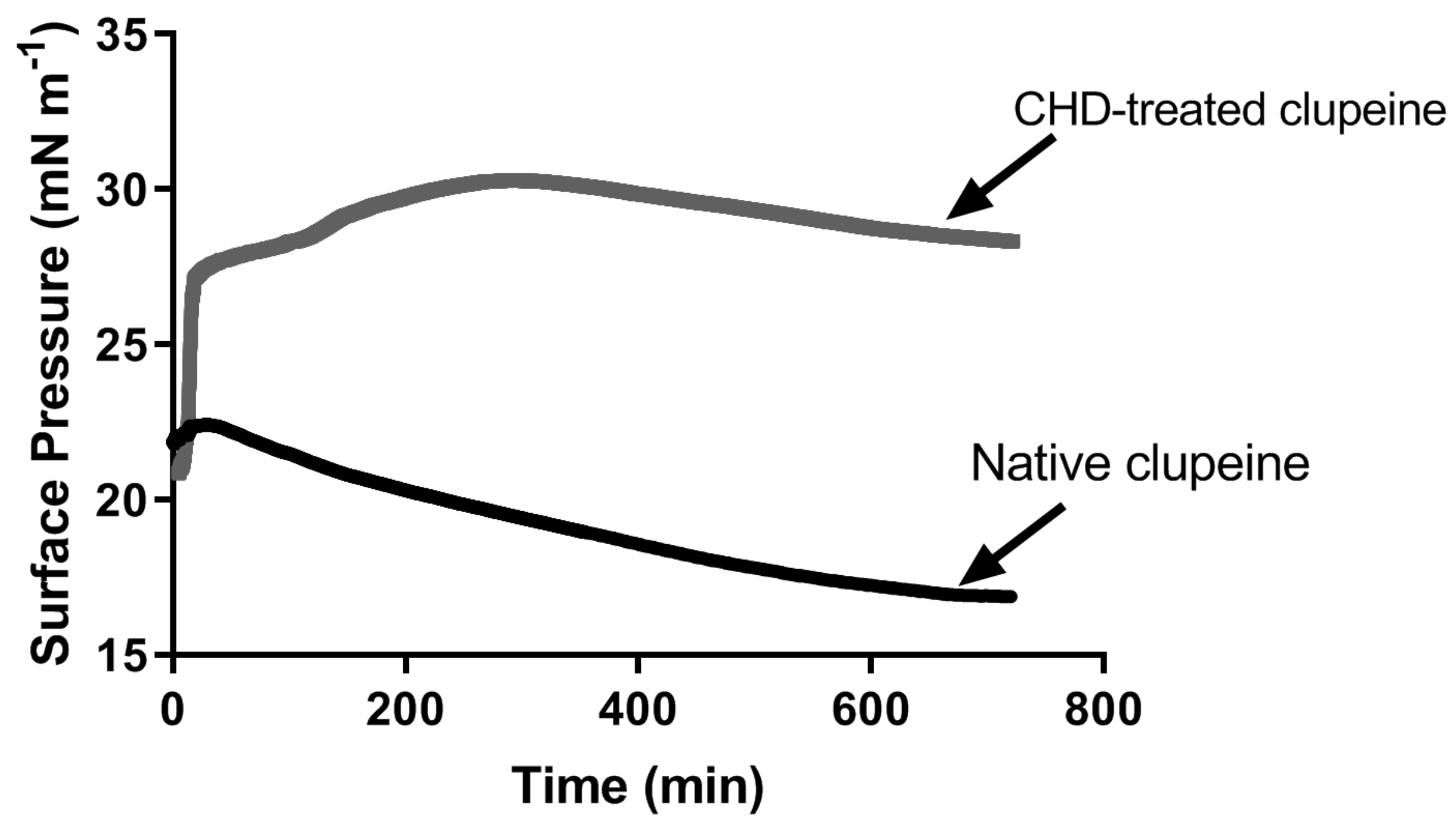


A.

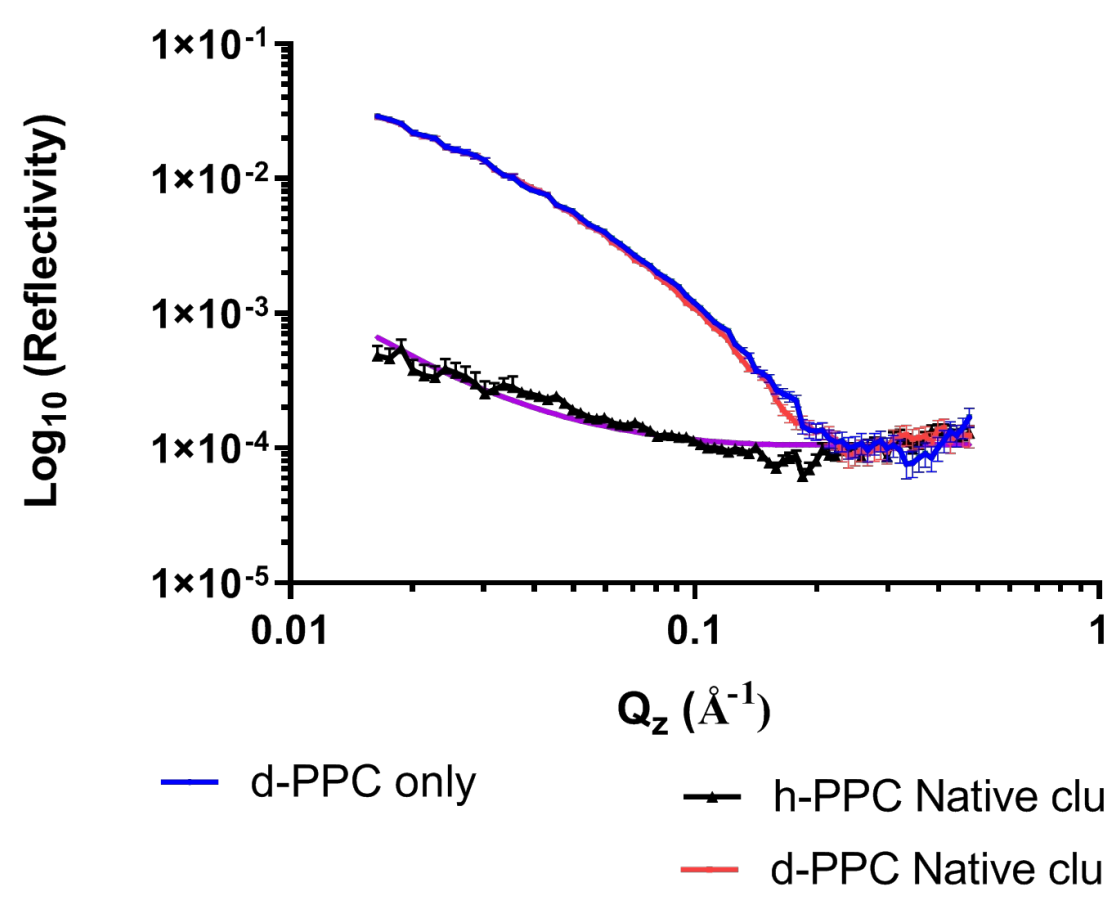

B.

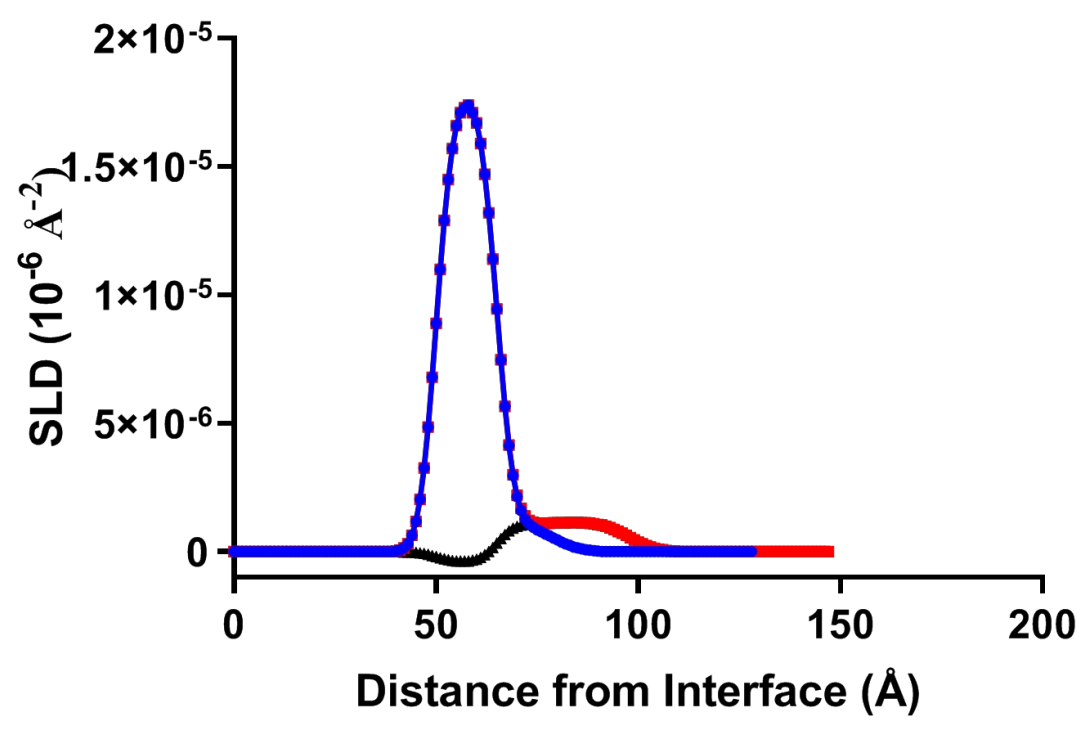

$\rightarrow$ d-PPC only

$\rightarrow$ d-PPC Native clu

- h-PPC Native clu 
A.

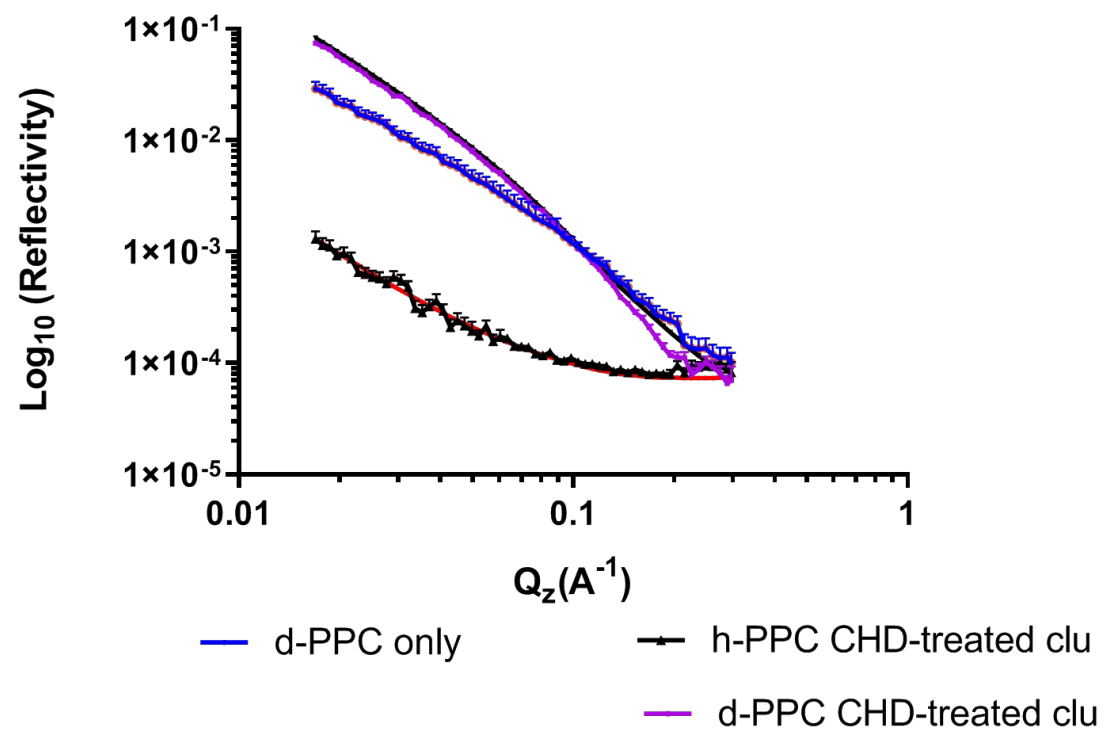

B.

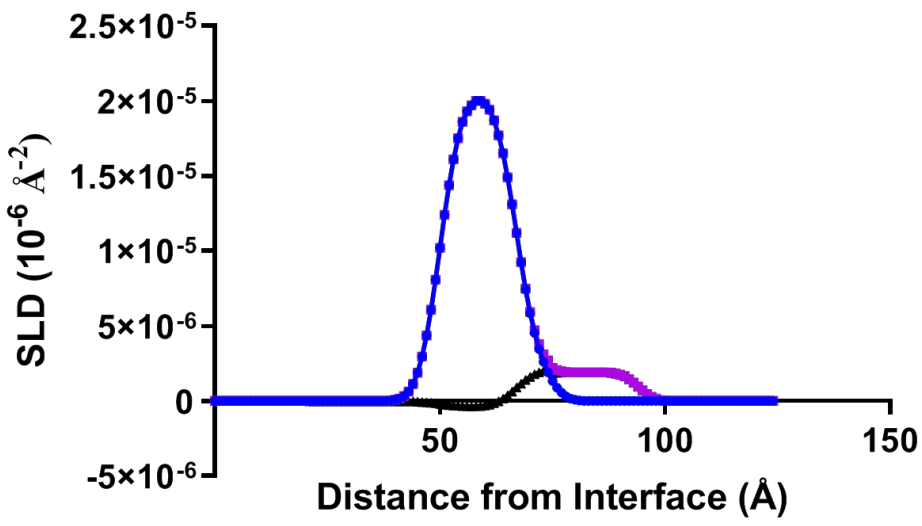

$\rightarrow$ d-PPC only

- h-PPC CHD-treated clu $=$ d-PPC CHD-treated clu 
A.

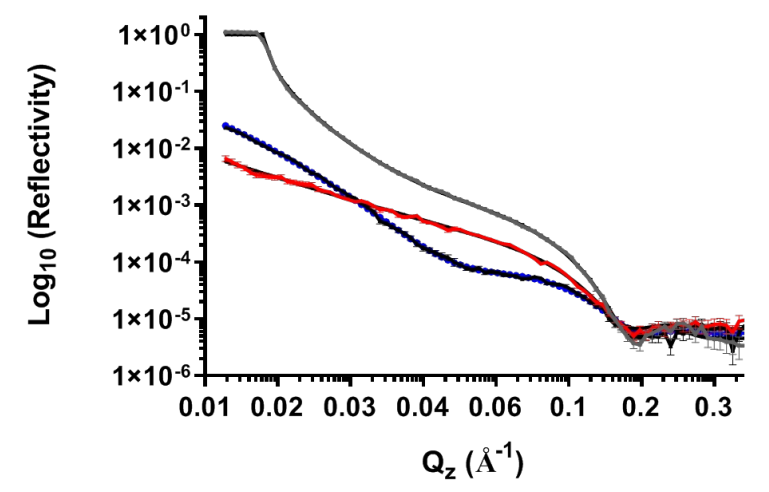

- Native clu- $\mathrm{D}_{2} \mathrm{O} \quad$ - Native clu-SMW

- Native clu- $\mathrm{H}_{2} \mathrm{O}$

C.

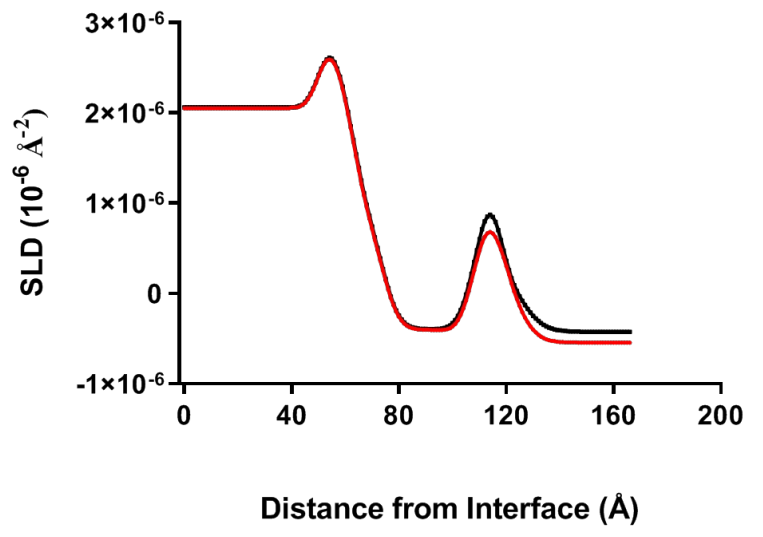

B.

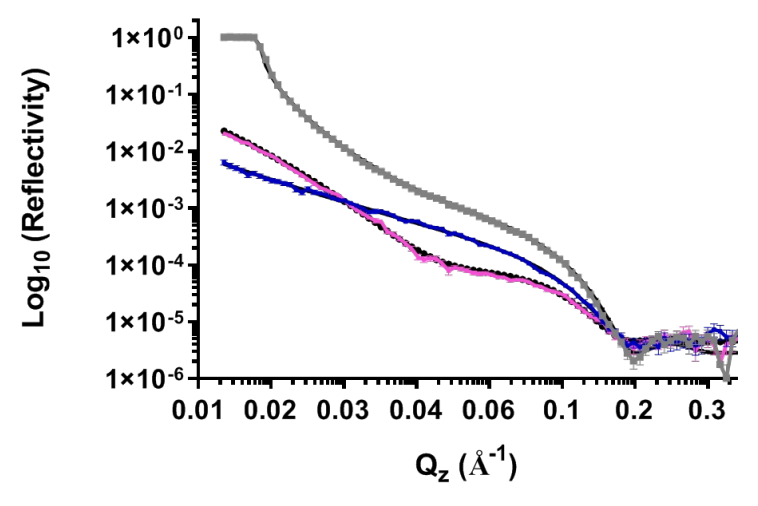

$\rightarrow$ CHD-treated- $\mathrm{D}_{2} \mathrm{O}-\mathrm{CHD}$-treated-SMW

- CHD-treated- $\mathrm{H}_{2} \mathrm{O}$

\section{D.}

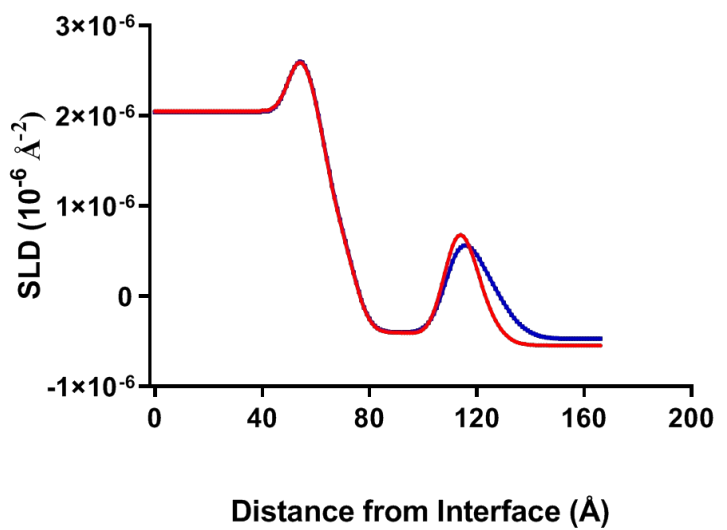

- h-DPPC:h-PPC- $\mathrm{H}_{2} \mathrm{O}$ - CHD-treated Clupeine- $\mathrm{H}_{2} \mathrm{O}$ 